\title{
Causal pathways from fractions to algebra: Integrating psychology and math education perspectives
}

\author{
Alexandria A. Viegut \\ Educational Psychology,, University of Wisconsin-Madison, Madison, United States; \\ Correspondence should be addressed to Alexandria Viegut, Department of Educational \\ Psychology, University of Wisconsin - Madison, 1025 W. Johnson St., Madison, WI \\ 53706. Email: aviegut@wisc.edu.
}

ORCiD: https://orcid.org/0000-0003-2608-3441 


\title{
Causal pathways from fractions to algebra: Integrating psychology and math education perspectives
}

\begin{abstract}
Algebra knowledge is an important gatekeeper to educational and economic opportunity. Both math education researchers and psychologists have shown that fractions may be a key to this gate (e.g., Hackenberg, 2013; Siegler et al., 2012). However, psychological and educational research on the fractions-algebra association has been disconnected, with separate frameworks, definitions, and designs. This integrative review synthesizes evidence from both disciplines about how and why fractions knowledge leads to stronger algebra knowledge. I suggest that the strength of causal evidence is limited by idiosyncratic measurement, limited longitudinal research, and imprecise definitions. I also review six plausible fractions-to-algebra mechanisms, which future research should empirically test. Throughout, I argue that more nuanced understanding of the fractions-algebra association will require interdisciplinary teams. Finally, I propose an integrative conceptual model of how fractions knowledge may lead to success in algebra and suggest new directions for collaborative investigation to inform developmental theory and educational practice.
\end{abstract}

Keywords: fractions; algebra; mathematics learning and teaching; measurement; cognitive development

Algebra is a "gatekeeper" in higher education in the U.S., with important consequences for social equity (Gamoran \& Hannigan, 2000; Matthews \& Fuchs, 2020; Moses \& Cobb, 2001). Students' access to and success in algebra is a prerequisite for higher level math and science classes, which are in turn essential for access to college and STEM careers (Burris et al., 2004; Chen, 2014; Dauber et al., 1996; Gamoran \& Mare, 1989; Trusty \& Niles, 2003). Unfortunately, many students have difficulty with algebra (National Center for Educational Statistics, 2019; Stigler et al., 1999). Students who struggle in algebra are more likely to drop out of high school, are less likely graduate college, and have lower lifetime earnings (Adelman, 2006; Kaput, 2008; Moses \& Cobb, 2001; RAND Mathematics Study Panel, 2003; Stigler et al., 1999). Thus, 
identifying foundational skills that support algebra competence is an important goal with meaningful consequences for students' educational and economic outcomes.

One robust and unique predictor of algebra performance is fractions knowledge. Indeed, many studies from psychology have shown that children's knowledge of fractions is a better predictor of their algebra scores than other foundational mathematical skills or domain-general abilities (Booth et al., 2014a; Booth \& Newton, 2012; DeWolf et al., 2015a; Hurst \& Cordes, 2018a; 2018b; Liang et al., 2018; Powell et al., 2019; Siegler et al., 2012). Separate work from math education has also shown that children's reasoning about fractions relates to their algebraic reasoning (e.g., Empson et al., 2011; Hackenberg, 2013; Hackenberg \& Lee, 2015; Tunc-Pekkan, 2008). However, psychological and educational research on the fractions-algebra association has remained remarkably disconnected, with separate definitions, measurement, designs, and theoretical frameworks. Research in both fields does have at least one thing in common: the explanation for the fractions-algebra association remains unclear. Why are fractions more important for algebra achievement than other foundational math skills? Which aspects of fractions are most important for understanding algebra, and which aspects of algebra do they support? How could future research designs test plausible causal explanations? In this paper, I take up these questions through a critical review and synthesis of relevant psychology and math education research.

This review synthesizes across theoretical perspectives and disciplines to put forth a nuanced theory of how fractions knowledge may lead to success in algebra. This question has important implications for educational policy and practice, and as such has received substantial attention from both psychology and math education, but the two strands of research remain detached. I approach this review as a psychologist, but I argue that a more nuanced model of the causal pathway from fractions to algebra will 
require interdisciplinary teams of researchers. Drawing upon psychology's methodological and analytical approaches and math education's deep investigation of mathematical constructs, this review summarizes what is known about the fractions-toalgebra association and reveals new avenues for collaborative investigation.

First, I review findings from psychology relating fractions knowledge to algebra knowledge, with attention to (a) current definitions and operationalizations of fractions and algebra knowledge and (b) the strength of causal claims linking the two. I then propose mechanisms which may potentially explain the fractions-to-algebra association, drawing on theories from both psychology and math education research. Next, I consider points of intersection among educational and psychological approaches to this question as well as points of methodological or substantive divergence. To conclude, I suggest directions for future interdisciplinary research that builds upon the strengths of both disciplines to better understand the connections between fractions knowledge and algebra.

\section{Evidence for a fractions-to-algebra pathway}

Children's knowledge of fractions is a better predictor of their algebra scores than other mathematical skills (e.g., whole number estimation and arithmetic) or domain-general abilities (e.g., working memory, nonverbal IQ, etc.) (Booth et al., 2014a; Booth \& Newton, 2012; DeWolf et al., 2015a; Hurst \& Cordes, 2018a; 2018b; Liang et al., 2018; Powell et al., 2019; Siegler et al., 2012). The correlation between fractions and algebra knowledge exists as early as 4th grade (Hurst \& Cordes, 2018a) and persists into adulthood (Hurst \& Cordes, 2018b; Powell et al., 2019). Despite this robust association, the strength of evidence that fractions knowledge causes algebra knowledge is more limited. In this section I will evaluate the causal evidence for a fractions-to-algebra pathway. 
To understand the relation between fractions knowledge and algebra knowledge, it is essential first to clearly define these constructs. My review of studies of the fraction-algebra relation will show that both types of knowledge have been vaguely defined and inconsistently measured. Arguably, this vagueness stems from problems with construct validity that are endemic to psychology. Indeed, it is rare in psychology to find deep treatment of fractions knowledge or algebra knowledge as constructs; instead, fractions and algebra often seem to be defined circularly by what we measure on fractions and algebra tests. Math education research, in contrast, has more explicitly defined the constructs and subconstructs of both fractions and algebra knowledge, but this work has been largely neglected by psychologists and has not been approached psychometrically. Future work in both disciplines should use clearer definitions and better measurement, which are essential to understanding the pathway from fractions to algebra.

\section{Defining and measuring fractions knowledge}

Fractions are a complex construct. Math education researchers describe fractions - or more precisely rational numbers - as a "mega-construct" (Kieren, 1980), which includes multiple subconstructs or interpretations (Behr et al., 1983; Charalambous \& Pitta-Pantazi, 2007; Kieren, 1976), including as part-whole comparison (e.g., 3/4 means 3 slices out of a whole pizza with 4 slices), as quotient (e.g., 3/4 means 3 divided by 4), as ratio (e.g., 3/4 means 3 apples : 4 oranges), as operator (e.g., $3 / 4$ means a scaling factor that I can multiply by 4 to get 3 ), or as measure on a number line (e.g., 3/4 means the distance that is $3 / 4$ of the way between 0 and 1 ). All of these subconstructs are "related, but only partially overlapping" (Ohlsson, 1988, p. 53). For students to develop robust fractions knowledge, they must understand and integrate several subconstructs. 
However, psychologists studying numerical cognition have often defined fractions knowledge more narrowly. Table 1 shows specific definitions and measures of fractions knowledge used in studies of the fractions-algebra association. [Table 1 near here.] As is evident from the table, not all fraction subconstructs are captured in studies of the fraction-algebra association. In fact, it is often difficult to pin down exactly which subconstruct(s) students are thinking of as they complete these fraction measures. Qualitative evidence from student interviews or strategy reports could shed light onto students' mathematical thinking, but this kind of work is relatively rare in psychology, especially with children (but see Rinne et al., 2017). As psychologists continue to investigate fraction learning, including the fractions-algebra association, it is important that we clearly define which aspects of fractions knowledge we do and do not seek to measure. This focus on definitions and construct validity will help psychologists to evaluate our common measures of fractions knowledge and consider aspects of fractions knowledge which may have been overlooked in prior work.

\section{Measuring knowledge of fraction magnitudes}

In psychological research relating fractions to algebra, the aspect of fractions knowledge that is most often highlighted is that of fraction magnitudes (e.g., Booth et al., 2014a; Booth \& Newton, 2012; DeWolf et al., 2015a; Hurst \& Cordes, 2018a; 2018b; Siegler, et al., 2011). To see the magnitude of a fraction, children must assign a single holistic value to the bipartite $\frac{a}{b}$ symbol. Rather than interpreting a fraction (e.g., 2/5) only as two distinct components (e.g., 2 pieces of a 5-part whole), children with magnitude knowledge can see its unidimensional magnitude (e.g., 0.4). This roughly corresponds to Kieren's (1976) “measurement” interpretation of a fraction. Many people struggle to develop understanding of fractions as magnitudes or measures (Byerley, 2019; Ni \& Zhou, 2005; Stafylidou \& Vosniadou, 2004; Stigler et al., 2010; 
Torbeyns et al., 2015). This is unfortunate, as scholars from multiple theoretical perspectives have argued that this knowledge is critical for children's expanding view of the number line and the continuity of all real numbers (e.g., Moss \& Cass, 1999; Siegler et al., 2011; Vamvakoussi et al., 2018).

Fraction number line estimation (NLE) is frequently used to assess fraction magnitude knowledge in psychological studies (Booth \& Newton, 2012; Booth et al., 2014a; DeWolf et al., 2015a). In this task, participants judge the magnitude of fractions by estimating their position along unmarked number lines that span from 0 to 1 . Siegler and colleagues' (2011) integrated theory of numerical cognition suggests that children have a gradually expanding "mental number line", and many psychologists have viewed NLE tasks as a direct window into this internal representation of numerical magnitudes (e.g., Booth \& Siegler, 2006; Siegler \& Opfer, 2003; Siegler \& Booth, 2004; Laski \& Siegler, 2007; Opfer et al., 2016). However, fraction NLE is a complex task, requiring not only fraction magnitude knowledge but factors like visuospatial skills, attention, cross-format proportion judgments, and benchmark strategies (e.g., Barth \& Paladino, 2011; Chesney \& Matthews, 2013; Cohen \& Quinlan, 2018; Hurst et al., 2014; Peeters et al., 2016; Slusser et al., 2013). As such, there is much debate among psychologists about what exactly is measured by whole number or fraction NLE tasks.

Whatever it measures, fraction NLE is a consistent predictor of algebra knowledge. Performance on 0-1 fraction NLE uniquely predicted concurrent algebra knowledge, as measured by problem solving and knowledge of equation features (e.g., negative sign, equals sign, like terms), in three separate studies of middle schoolers (Booth \& Newton, 2012; Booth et al., 2014a; DeWolf et al., 2015a). These three studies of the fraction-algebra relation using NLE used the same protocol and nearly identical stimuli. Participants estimated fractions along 0-1 number lines in an untimed paper- 
and-pencil test. The target fractions included unit fractions (e.g., 1/5), familiar non-unit fractions (e.g., 3/5), and unfamiliar non-unit fractions (e.g., 33/47). Other research has also measured fraction magnitude knowledge using different target fractions, ranges (i.e., 0-2 or 0-5), and formats (i.e., computerized) (e.g., Hansen et al., 2015), but no study has investigated the link between algebra and fraction estimation on these tasks.

Psychologists have also often assessed fraction magnitude knowledge with magnitude comparison tasks, in which participants select the greater of two fractions (e.g., 3/7 vs. 2/3). Children's fraction comparison performance uniquely predicts algebra skills, like solving for unknowns and finding patterns in data tables (Hurst \& Cordes, 2018a), in addition to overall math achievement (Bailey et al., 2012; Hansen et al., 2017a; 2017b; Torbeyns et al., 2015). Children's accuracy on a cross-notation magnitude comparison task comparing fractions to other types of numbers (i.e., whole numbers and decimals) was also a significant predictor of pre-algebra knowledge in $4^{\text {th }}-$ $7^{\text {th }}$ grade children (Hurst \& Cordes, 2018a). Children's accuracy on the cross-notation magnitude comparison task was a stronger predictor of algebra knowledge than rational number arithmetic was. However, when a similar design was tested with adults, only fraction arithmetic - not magnitude knowledge - significantly predicted algebra performance (Hurst \& Cordes, 2018b).

Hurst and Cordes's diverging results with $4^{\text {th }}-7^{\text {th }}$ grade children (2018a) and undergraduate adults (2018b) illustrate the importance of measurement choices in fractions-to-algebra research. Ostensibly their results suggest that fraction magnitude knowledge may matter more for algebra skill among children than adults. However, closer examination suggests that these divergent findings may have been due to differences in measurement. Even though both studies used similar designs, Hurst and Cordes's (2018a) study with children used cross-notation (i.e., decimal-fraction, whole 
number-fraction, and whole number-decimal) comparisons, and their adult study (Hurst \& Cordes, 2018b) used only within-notation comparisons. The cross-notation task (e.g., 5/7 vs. 0.283 ) may elicit more holistic processing of fraction magnitudes, whereas the within-notation comparisons (e.g., 5/7 vs. 3/8) can be solved by many strategies, some of which bypass the holistic value of the fraction (e.g., Obersteiner \& Tumpek, 2016). Further, Hurst \& Cordes's (2018a) child study used a composite score of average percent correct on the comparison tasks, whereas the adult study used different outcomes (e.g., response times). Both studies suggest that fraction magnitude and arithmetic contribute to algebra knowledge. However, they make diverging conclusions about the relative importance of magnitude and arithmetic, which is difficult to interpret given their differences in measurement. This example illustrates the power of our choices as scientists - our conclusions are dependent upon which measures we use, how we score those measures, and which results we report in published work.

\section{Measuring knowledge of fraction arithmetic}

Whereas fraction magnitude knowledge is consistently measured via number line estimation and comparison, fraction arithmetic knowledge has been less explicitly defined and more variably measured. Fluent fraction operations, measured in a variety of ways, have been shown to correlate with algebra knowledge in multiple age groups (Booth et al., 2014; Hurst \& Cordes, 2018b; Liang, et al., 2018; Powell et al., 2019) and across countries (Siegler et al., 2012). Two of these studies showed a longitudinal relation (Liang et al., 2018; Siegler et al., 2012). Both longitudinal studies constructed measures of fractions knowledge by selecting subsets of items from existing standardized tests. However, if a test is not explicitly designed with a fraction subtest (e.g., the Woodcock-Johnson test used by Siegler and colleagues), it has questionable validity as a fraction measure. Additionally, two single-session studies used unique 
researcher-constructed measures of fraction arithmetic (Hurst \& Cordes, 2018a; 2018b; Powell et al., 2019). These scales are idiosyncratic and make comparing effects between studies difficult. This lack of rigor in measuring fractions knowledge is endemic to psychology and almost certainly has detrimental effects on the research.

\section{Moving toward clarity and depth in fractions measurement}

Psychology's measures of fractions knowledge are rapid, replicable, and easy to administer, but tend toward weak construct validity. In psychology studies, there is typically no deep treatment of the fractions construct or the relative difficulty of its subconstructs. A construct map, like the one psychologists have created for math equivalence (i.e., understanding of the equal sign; Matthews et al., 2012; Rittle-Johnson et al., 2011; Fyfe et al., 2018), could guide new, theoretically-grounded assessments of fractions knowledge. It would also deepen our understanding of the order in which children's knowledge of fractions is constructed.

As psychologists consider the construct validity of their fraction measures, they should draw upon the extensive literature on fractions knowledge from math education research. In contrast to psychology, math education research on fractions has carefully considered the constructs and subconstructs of fractions. However, many of these rich assessments are not well suited for exploring quantitative models of the fractionsalgebra relation. Math education researchers have often examined the development of fractions knowledge through smaller-scale teaching experiments and interviews. For example, Steffe (2002) and others have identified a hypothetical learning trajectory of children's fraction schemes - their cognitive frameworks for experiencing and interacting with fractions (e.g., Confrey et al., 2014; Hackenberg, 2007; Steffe \& Olive, 2010; von Glasersfeld, 1995). This learning trajectory progresses from simpler schemes, such as partitioning a whole into equal parts, to more complex schemes which include 
iterating and reasoning about reciprocals with proper and improper fractions (Hackenberg, 2013; Norton \& Wilkins, 2009). Typically, education researchers assess children's fraction schemes qualitatively through in-depth interviews or small-group learning activities (e.g., Hackenberg, 2007; 2010; 2013; Hackenberg \& Lee, 2015; Norton \& Hackenberg, 2010; Thompson \& Saldanha, 2003). Some efforts have been made to create written quantitative instruments to assess these schemes (Charalambous \& Pitta-Pantazi, 2007; Norton \& Wilkins, 2009; Norton et al., 2015; Wilkins et al., 2013), but no study has analyzed their relation to algebra knowledge. It also remains unclear how these fraction schemes and learning trajectories correspond to the fraction magnitude and arithmetic knowledge measured by psychologists.

\section{Defining and measuring algebra knowledge}

Like fractions knowledge, algebra knowledge is a broad and complex construct that is often ill-defined in psychological research. It is essential to improve the clarity of definitions and specificity of measures to progress towards a better understanding of how and why fractions help students with algebra. In this section, I will review perspectives on defining and measuring algebra from math education and psychology. I will then argue for interdisciplinary future fractions-algebra research that uses theoretically-grounded assessments and attends to students mathematical thinking. Algebra is more than solving for " $x$ "

Many psychologists draw from Algebra I textbooks to create omnibus measures of algebra knowledge, but the algebraic thinking that becomes formalized in algebra class begins to develop much earlier, even before children learn fractions. Long before they can solve for $x$ or graph systems of equations, young children demonstrate algebra knowledge as they generalize, notice patterns in mathematical structures and relations, and begin to think about functions in elementary school mathematics (see Kieran et al., 
2016 for a review). Although formal algebra instruction has traditionally begun in middle or early high school, reforms across the globe in the past few decades have pushed for algebraic thinking to be taught as early as kindergarten (e.g., Cai \& Knuth, 2011; Carpenter et al., 2003; Kaput, 1998; National Council of Teachers of Mathematics, 2000). Indeed, Operations and Algebraic Thinking is a strand of the Common Core mathematics standards that extends throughout the K-12 range (NGA, 2010). The "early algebra" movement shows the breadth and depth of the construct of algebra knowledge.

Although existing fractions-algebra research has largely focused on formal symbolic algebra as an outcome, the expanded attention to early algebraic thinking in research and in schools suggests that future research ought to consider other ways students can demonstrate knowledge of algebra. Algebraic thinking can take such different forms as preschool students generalizing a pattern of repeating pictures (e.g., Zippert et al., 2020) or high school students writing an equation to represent the line connecting two points. Algebraic thinking is often represented with formal alphanumeric symbols, but it can also be represented with student drawings or natural language (e.g., Blanton et al., 2019; Carraher et al., 2008). For example, Blanton and colleagues (2019) asked $3^{\text {rd }}$-graders to talk about equations like $38+\ldots=\ldots+38$ to explore the commutative property. What numbers make this equation true? Students who are able to describe in words that any number would make the equation true, as long as it is the same number in both blanks, are using algebraic thinking even if they are not using the formal notation with variables (e.g., $38+x=x+38$ ). Similarly, students can use blocks or drawings to reason about generalizable properties of arithmetic, such as that the sum of any two odd numbers is even (Blanton et al., 2015). What are the core aspects of algebra? 
In recent decades, scholars from math education have theorized deeply about the nature of school algebra - its contents, its representations, its thinking practices, and its development (e.g., Blanton et al., 2015; 2018; Blanton \& Kaput, 2011; Cai \& Knuth, 2011; Carraher et al., 2008; Clements \& Sarama, 2014; Knuth et al., 2005; Koedinger et al., 2008; Nathan \& Koellner, 2007; Nathan, et al., 2002; Stephens et al., 2017). In the math education research tradition, algebra can be distinguished from arithmetic and other realms of mathematics by its focus on three "big ideas": generalized arithmetic, functional thinking, and equivalence (Blanton et al., 2018; Kaput, 2008). Generalized arithmetic (Blanton et al., 2015; Stephens et al., 2017) involves noticing and representing patterns, properties, or structures that "hold for a large set of mathematical objects or conditions" (Carraher et al., 2008, p. 3). Functional thinking involves attending to and representing relations between two or more varying quantities (Blanton \& Kaput, 2011). The third "big idea" of algebra is "EEEI" (Shin et al., 2009; Blanton et al., 2018), a broad category covering equivalence, expressions, equations, and inequalities. Algebra requires an increased focus on the meaning of the equal sign as a relational symbol (i.e., indicating equivalence on both sides) rather than as an operator (i.e., indicating a computational process on one side and an "answer" on the other side) (Knuth et al., 2006; MacGregor \& Stacey, 1993; Matthews et al., 2012; Sfard \& Linchevski, 1991; Steinberg et al., 1990). Within all three of these core concepts, algebra gradually introduces children to variables, abstract symbols to stand for unknown quantities that may vary. As discussed previously, students can express algebraic thinking through many representations or models - verbal, pictoral, physical, etc. (Blanton et al., 2018; 2019; Cai \& Knuth, 2011; Radford, 2000), but even young students may benefit from the symbolic language of variables as they learn to reason algebraically (Brizuela \& Earnest, 2017). 
In addition to these three core content areas, math education researchers have also identified core practices or "habits of mind" that are involved in algebra (e.g., Blanton et al., 2018; Driscoll, 1999; Goldenberg, et al., 2010; Goldenberg et al., 2015; Kieran, 2007; Papadopoulos, 2019). For instance, Blanton and colleagues (2018) suggest that the four essential practices of algebraic thinking are "generalizing, representing, justifying, and reasoning with mathematical structure and relationships" (p. 30). In a parallel vein, Kieran (2007) has defined school algebra as consisting of three types of activities: generational (i.e., forming expressions and equations), transformational (i.e., changing the symbolic form of an expression or equation to maintain equivalence), and global (i.e., problem solving, justifying and proving, looking for relationships, etc.). These practices and activities seem to have some connection to psychology's measurement of algebra. For example, equation writing or word problem solving involve representing or generating, whereas equation solving involves justifying and transformation. However, neither the definitions of algebra from math education researchers nor the measures developed based on these definitions (e.g., Blanton et al., 2018) have been invoked by psychologists in measuring the fractions-algebra relation.

\section{Measuring algebra knowledge in psychology}

Despite all of the work from math education researchers to define the core areas and practices of algebraic thinking, psychologists often use omnibus tests to measure algebra knowledge, drawing from standardized tests or Algebra I textbooks. These omnibus measures estimate students' algebra performance with relatively high ecologically validity, but they are typically not designed to assess specific aspects of algebra knowledge or depth of algebraic reasoning. Although some studies break algebra measures into more specific subtests (e.g., Booth \& Newton, 2012), it is unclear whether these studies capture appropriate breadth or depth of students' algebra 
knowledge, because the boundaries and constituent parts of the construct are often poorly defined.

Many psychological studies have not explicitly attempted to define algebra. There are notable exceptions, such as Powell and colleagues (2019), who define algebra as recognizing "patterns and relationships between sets" and eventually reasoning with "simple functions and solving equations with missing parts" (p. 1). Psychology has also extensively researched children's understanding of equivalence and the equal sign, one of the core concepts of algebra (e.g., Byrd et al., 2015; Matthews \& Fuchs, 2020; McNeil, 2014; Rittle-Johnson et al., 2011). However, other studies from psychology, including investigations of the fractions-to-algebra relation, tacitly consider algebra to be whatever Algebra I teaches or whatever algebra tests measure. The lack of clear definitions may be especially problematic when researchers use self-constructed measures, such as including a combination of new and existing items culled from a variety of sources without a guiding definition of the construct. This is common practice in psychology in fractions-algebra research (e.g., Booth \& Newton, 2012; Booth et al., 2014a; Hurst \& Cordes, 2018a; Siegler et al. 2012) and algebra research more generally (e.g., Koedinger et al., 2008; Matthews \& Fuchs, 2020; Simsek et al., 2019).

All researchers need not use identical measures; rather, I suggest that researchers should be clear about what constructs our algebra assessments aim to measure and which aspects of algebra they may not capture. For example, Matthews \& Fuchs (2020) measured "algebraic knowledge" with two types of items (i.e., equation solving and function tables). However, because they did not make it clear which aspects of algebra they wanted to measure, it is difficult to justify why they included these items instead of (or in addition to) asking children to give strategy reports, solve word problems, judge features of equations, justify why a particular procedure works, or engage in any other 
type of algebraic reasoning. Without an explicit definition of algebra, there is no clear guide for the selection of items or construction of algebra measures.

Despite the murkiness of its definition, there are some consistencies in the ways psychological studies tend to measure algebra knowledge, as seen in Table 2. Equation solving (e.g., $-3 y+6=8+5 y$; Booth et al., 2014a) and expression evaluation (e.g., evaluate $2 a+3(2-b)$ given $a=3, b=1$; Hurst $\&$ Cordes, 2018b) are common. These types of problems assess students' knowledge of algebraic rules and notation, and they align with the way algebra performance is measured on standardized achievement tests. However, equation solving or evaluation problems in psychology typically score students' answers but not their reasoning. Strategy use is rarely measured for such problems, so students using a "guess and check" strategy or those using rote algorithms without much understanding could plausibly receive the same score as students with a deep understanding of algebraic properties. Thus, unlike the in-depth interviews or written explanations used to assess algebra in math education research, assessments from psychology may not adequately measure the four core practices of algebraic thinking described above (Blanton et al., 2011). [Insert Table 2 near here].

Some psychological measures of algebra aim to assess conceptual knowledge more directly. Multiple studies have tested feature knowledge, such as naming and defining the equals sign, identifying variable terms versus constant terms, and correctly interpreting terms with a negative sign (e.g., "Is 6 a like term for $6 c$ ?") (Booth \& Newton, 2012; Booth et al., 2014a; DeWolf et al., 2015a). Attention to critical features of algebraic equations can also be measured through equation encoding tasks in which students see an equation for a few seconds and must reconstruct the problem from memory (Booth et al., 2014a; McNeil \& Alibali, 2004). This task can reveal errors in encoding conceptual features (e.g., misplacing the equals sign, dropping a negative sign, 
changing an operation, etc.). Other tasks used in psychology to measure algebraic thinking include equation writing and word problem solving. For example, Hurst and Cordes (2018b) showed children a table of corresponding $A$ and $B$ values as shown in Table 2. Children were then asked to write the rule used in the table (correct answer: $B$ $=A+4)$. Similarly, word problem solving tasks describe a relation without providing a symbolic equation. To answer word problems correctly, participants may use any strategy (e.g., drawing, symbolic equation, multiple arithmetic equations, guess and check, etc.). The common algebra tasks described above and summarized in Table 2 measure some specific aspects of algebra, but it remains unclear how these psychological tasks map onto the core areas and algebraic thinking practices identified by math education researchers.

Psychologists have done important work to identify fractions as a particularly strong predictor of algebra knowledge, even when statistically controlling for other skills. However, many of the most popular measures of algebra knowledge from psychology emphasize solutions over strategies and rest upon imprecise definitions of the algebra knowledge construct. Thus, these measures may be ill-suited for measuring the construct in all of its breadth. Lack of construct validity in measures of algebra knowledge, like in fractions measures, is a potentially serious threat that limits our understanding of the connection between these types of knowledge.

\section{Moving toward specificity and depth in algebra measurement}

As research continues to explore the connections between fractions and algebra - and the development of algebraic thinking more generally - it is essential that we explicitly define and carefully measure the specific components of algebra knowledge. Math education research has outlined core aspects and practices of algebraic thinking, but these are typically measured with in-depth individual assessments that are not 
conducive to large-scale studies or statistical modeling. Psychology has developed measures that align with achievement tests and can efficiently measure summative algebra performance quantitatively, but it is usually unclear which areas of algebra are being measured. Future research should build on the strength of both disciplines to more clearly define and measure algebra knowledge using replicable, mixed-methods, theorybased measures. Such measures could be explicitly geared to measure different components or subconstructs.

One way for this interdisciplinary work to start is for psychologists and math education researchers to work together to map existing psychological tasks to the core areas (generalized arithmetic, functional thinking, and EEEI) and practices (generalizing, representing, justifying, and reasoning with mathematical structure and relationships) of algebra. For example, does equation encoding, in which students write down an equation which they saw flashed for a few seconds, capture the subconstruct of equivalence? Which (if any) core practices are captured by equation encoding? If researchers can agree, for example, that equation encoding captures some understanding of equivalence and the core practice of representing, then they can map out which other tasks should be included to more fully capture all the important areas of algebra and algebraic thinking. Thinking carefully about the specific constructs each task is designed to measure, in combination with psychometric tools like item response theory (IRT) (e.g., Matthews et al., 2012) and factor analysis (e.g., Jones et al., 2012; Rinne et al., 2017), will improve the construct validity of algebra measures. In many cases, interview data or written explanations may be necessary to probe the depth of students' algebraic reasoning.

In sum, many studies exploring relations between fractions knowledge and algebra knowledge have used assessments that have not fully considered the 
subconstructs within each of these larger constructs. There is also wide variability in which types of tasks are used to operationalize both types of knowledge. With questionable construct validity and inconsistent measures, it is difficult to synthesize results across studies to know which aspects of fractions and algebra knowledge relate most closely. Often, fractions-to-algebra research starts from existing ways of testing and extrapolates to a construct, instead of starting by clearly defining the construct and thinking about how it could be measured. This is not simple; both fractions knowledge and algebra knowledge are complex, multifaceted constructs. Definitions and measurement vary widely across studies in psychology. When also considering the extensive literature from math education, the diversity of thought about what constitutes "fractions knowledge" and "algebra knowledge" varies even more widely. Agreement across all researchers is not imperative, but clarity is. Researchers of different perspectives need not agree upon a single definition or measure, but they do need to be explicit and precise about their choices. As research on the fractions-algebra association continues to expand, this clarity will make claims clearer, testing easier, and metaanalyses more reliable. It may also help to make clear which aspects of fractions and algebra knowledge have been missing in existing measures.

\section{Strength of causal evidence}

As we strive to improve definitions and measurement, we must also consider what counts as causal evidence. What evidence would support the conclusion that fractions knowledge causes algebra knowledge? To establish causality, studies must first establish a fractions-algebra correlation, rule out plausible alternative explanations using statistical controls or experimental manipulation, and use longitudinal designs to establish temporal ordering. Indeed, as reviewed above, a significant correlation between fractions and algebra knowledge has been found in at least eight psychological 
studies (Booth \& Newton, 2012; Booth et al., 2014a; DeWolf et al., 2015a; Hurst \& Cordes, 2018a; 2018b; Liang et al., 2018; Powell et al., 2019; Siegler et al., 2012). The strength of the zero-order correlation varies across studies and within studies by operationalization, with correlation coefficients ranging from .23 (Booth et al., 2014a) to .71 (Powell et al., 2019). Correlations have been found across age groups from $4^{\text {th }}$ grade (Hurst \& Cordes, 2018a) to college students (Hurst \& Cordes, 2018b; Powell et al., 2019), and with varying amounts of time between the test of fractions knowledge and algebra knowledge. Most studies measure fractions and algebra concurrently, but the association has also been found when algebra is measured a few weeks (Booth et al., 2014a), 1 year (Liang et al., 2018), and 5-6 years later (Siegler et al., 2012). [Figure 1

\section{near here.]}

Given the consistent correlation, what additional evidence is necessary? At a minimum, a study must rule out the most plausible alternative explanations. The relation between fractions knowledge and algebra knowledge must persist even when we account for shared predictors (Figure 1a). Because fractions and algebra are both subdomains of mathematics, they are likely to be influenced by many of the same predictors. Variables like earlier math and language skills, domain-general cognitive skills, and school and family background are likely to influence both fraction and algebra learning. To isolate the effect of fractions on algebra, studies include some of these predictors. Most commonly, studies show that the fraction-algebra relation persists even when statistically controlling for whole number knowledge or other mathematical skills (Booth \& Newton, 2012; Booth et al., 2014a; DeWolf et al., 2015a; Hurst \& Cordes 2018a; 2018b; Siegler et al., 2012).

If we assume that other math skills are also influenced by the same predictors that are shared between fractions and algebra, then these controls would greatly improve 
the strength of causal claims. However, it is likely that as math increases in complexity (e.g., fraction arithmetic and algebraic problem solving are more complex than whole number arithmetic), it requires greater domain-general cognitive skills. Similarly, family background or school resources might have different effects on later math subdomains like fractions and algebra than earlier subdomains. Therefore, the causal claim is weaker in studies which fail to control for domain-general skills, language, or contextual factors like socioeconomic status. Three studies of the fractions-algebra association show that the relation does persist even when controlling for nonverbal IQ, working memory, family background, math anxiety, and language skills (Liang et al., 2018; Powell et al., 2019; Siegler et al., 2012). Even with many controls, fractions knowledge still explained $33 \%$ of the variance in algebra for middle school students (Liang et al., 2018) and 48\% of the variance for college students (Powell et al., 2019). Although it is never possible to rule out all confounding variables, the fraction-algebra relation does not seem to be fully explained by shared predictors.

In addition to ruling out plausible third variables that may inflate the fractionsalgebra association, causal evidence needs to establish temporal ordering. That is, if fractions and algebra are measured at the same time, there is no way to know the direction in which causality flows: does better fractions knowledge lead to stronger algebra skill (Fig. 1b) or vice versa (Fig. 1c)? Existing research has considered fractions knowledge as the predictor and algebra as the outcome, which seems reasonable on its face if fractions are learned around $3^{\text {rd }}$ or $4^{\text {th }}$ grade and algebra is learned later in middle school or early high school. But as I have reviewed, early algebra instruction can begin as early as kindergarten (e.g., Blanton et al., 2018), and both fractions and algebra are long-developing mathematical skills (e.g., Stigler et al., 2010). Thus, it is possible that practice with algebraic thinking improves understanding of fractions. This possibility 
has not yet been investigated. Alternatively, fractions and algebra understanding may codevelop over time (Fig. 1d), each facilitating learning of the other. Indeed, evidence supports a bidirectional relation between fractions knowledge and general math achievement (Hansen et al., 2017b). A similar analysis has not yet been conducted between fractions and algebra knowledge.

To date, only three longitudinal studies have been conducted to explicitly test the hypothesis that better fractions knowledge causes better algebra outcomes. Siegler and colleagues (2012) used two large datasets from Britain and the U.S. to study the relation between fraction understanding at age 10 and algebra understanding 5-6 years later. Relative to other math skills, knowledge of fractions was the strongest predictor of algebra performance, even after controlling for IQ, working memory, and socioeconomic background. This highly-cited finding often motivates psychological studies of fraction learning and mathematical cognition. The large sample size $(\mathrm{n}=$ 3,677 British; $\mathrm{n}=599$ U.S.), five-year longitudinal design, and consistent finding across two datasets lend substantial strength to the causal argument. However, the study's measurement of the key variables was limited due to the use of secondary data. In both U.S. and British samples, fractions and algebra knowledge were culled from a small number of selected items on larger math tests, and the psychometric properties of these constructed subscales is not reported. Thus, although Siegler and colleagues (2012) provide strong evidence for a causal relation between their measures of fractions knowledge and algebra knowledge, this influential study has questionable validity due to unclear definitions and measurement of both types of knowledge.

The second longitudinal study of the fractions-to-algebra relation was conducted to test whether fractions knowledge predicted the extent to which children learned algebra from subsequent instruction. Booth and colleagues' (2014a) study of Algebra I 
students $(n=72)$ showed that fraction magnitude knowledge at the start of a unit with a personalized Cognitive Tutor predicted learning gains in algebraic equation solving and encoding at the end of the unit ( 1-3 weeks later). This shorter study demonstrated a trait by treatment interaction whereby children with better fractions knowledge benefitted more from algebra instruction. It remains unclear whether this generalizes to algebra instruction without the Cognitive Tutor.

Finally, Liang and colleagues (2018) studied nearly $200,0007^{\text {th }}$ grade students over 1 year. Students' performance on the rational number subtest of a state standardized test explained $48 \%$ of the variance in their Algebra I scores the following year, even when controlling for other $7^{\text {th }}$ grade math subtests and demographic characteristics. This study provides evidence for a fractions-to-algebra relation with a large sample and ecologically valid measures. Like the other longitudinal studies, it adds confidence to the causal fractions-to-algebra claim. However, Liang and colleagues' (2018) estimate of the association may be inflated by shared measurement bias (i.e., both fractions and algebra were measured in school-administered multiplechoice tests) and unmeasured variables (e.g., language, working memory, etc.). Like the other psychological studies of the fractions-algebra association, Liang and colleagues (2018) measured algebra using items that rely heavily on formal algebraic notation. It remains unclear how strongly fractions knowledge is associated with early algebra knowledge or algebraic reasoning with informal representations.

To recap, fractions knowledge is consistently associated with concurrently measured algebra knowledge, and there are three studies showing that fractions knowledge predicts later algebra outcomes. All studies to date have used nonexperimental designs, instead using statistical controls to isolate the effect of fractions knowledge. However, the strongest causal evidence for a fractions-to-algebra pathway 
would involve an experimental manipulation of fractions knowledge. Many interventions have boosted children's fractions knowledge (e.g., Barbieri et al., 2019; Fazio et al., 2016; Fuchs et al., 2013; Hamdan \& Gunderson, 2017), but no study has examined the effect of these interventions on later algebra outcomes. In fact, most fraction interventions only test learning immediately after the intervention, so little is known about the persistence of their effects over time even on fractions knowledge itself. An experiment showing that improvements in fraction understanding lead to later improvements in algebra would provide the strongest evidence for a causal role of fractions knowledge in algebra learning. Such an intervention experiment could simultaneously advance psychological theory and educational practice (Rosenberg-Lee, 2018).

\section{Plausible mechanisms connecting fractions and Aagebra}

To strengthen the claim that fractions knowledge leads to stronger algebra knowledge and to identify possible points of intervention, it is important to isolate and test plausible steps along the causal pathway. Most of the psychological studies of the fractionalgebra association reviewed in the previous section offered some suggested mechanisms, and math education researchers have proposed others as well. However, these bodies of literature have been relatively isolated. This section will summarize and synthesize proposed explanations for the fractions-to-algebra link from both disciplines. These mechanisms, listed in Table 3, are neither exhaustive nor mutually exclusive. There are many possible explanations for the fractions-algebra relation, and the association likely works through multiple mechanisms. As future research aims to better understand the associations between fractions and algebra, these explanations should all be considered. [Table 3 near here.] 


\section{Mechanism 1: Deeper understanding of the number system}

As reviewed above, algebra is a way to model and reason about mathematics abstractly, using generalizable principles and properties. One reason fractions knowledge may be useful for algebra is that it facilitates reasoning about numbers in a generalizable way. The integrated theory (Siegler et al., 2011) and framework theory (Vamvakoussi et al., 2018) of numerical cognition suggest that children's conceptualization of the number system broadens as they learn to view fractions as numbers with magnitudes that can be represented on a number line. A deep understanding of fraction magnitudes requires students to understand which properties apply to all real numbers (e.g., each number has a magnitude) and which properties are specific to whole numbers (e.g., each number has a unique successor). Students must also learn that the same magnitude can be mapped to many different symbolic representations (e.g., $3 / 4=6 / 8=75 / 100=141 / 188=0.75$ ). In this way, fractions are an important opportunity for students to reason about the structure of the number system and the generalizable properties of numbers.

An understanding that fractions are part of the number system may also help children overcome "natural number bias" (Obersteiner et al., 2013) in algebraic thinking. If a child can think about a fraction as a number, with a magnitude that can be represented on the number line with all other numbers, they may be more flexible in interpreting variable expressions. Many children have a hard time imagining that unknown variables in algebraic expressions can stand for numbers other than positive integers (Christou \& Vosniadou, 2012). Even students who understand that variables can represent "any number" may struggle to solve equations like " $4 b=3$ " or " $3-x=$ 7", because their conceptual framework for "any number" only includes any natural number (Christou and Vosniadou, 2012). It can be hard to imagine substituting a fraction for $b$ or a negative number for $x$, especially because the single letter notation for the variable does not visually match the multi-part notation of a fraction or negative 
number. Children who can more easily view a fraction as number with a magnitude may more easily solve these types of equations. This flexible view of variables may also confer an advantage later in algebra learning when students must substitute complex expressions for a single variable, as in solving systems of equations by substitution (Figure 2). [Figure 2 near here.]

If understanding that fractions are numbers with magnitudes is an important mechanism connecting fractions knowledge to algebra, then one might expect decimal knowledge to also predict algebraic skill. Decimals and percentages represent rational number magnitude more directly and unidimensionally than fractions (DeWolf et al., 2015b) in a way that more closely follows conventions for representing whole numbers (DeWolf et al., 2014). Empirical evidence is mixed, with at least one study showing that decimal number line estimation more strongly predicts algebra knowledge than fraction number line estimation (DeWolf et al., 2015a), and a similar study showing the opposite: that children's fraction comparison performance, but not decimal comparison, explained significant variance in their algebra scores (Hurst \& Cordes, 2018a).

However, recommendations from the National Mathematics Advisory Panel (2008) and from math education researchers (Hackenberg, 2013; Hackenberg \& Lee, 2015; Peck \& Matassa, 2016) suggest that it is fraction notation specifically, not rational number in general, that sets the stage for algebra learning. Indeed, many researchers argue that there is something specific about the bipartite, $\mathrm{a} / \mathrm{b}$ notation that is particularly helpful for supporting algebraic reasoning (DeWolf et al., 2015a; 2016; Empson et al., 2011; Hackenberg, 2013; Hackenberg \& Lee, 2015; Matthews \& Ellis, 2018; Nabors 2003; Tzur, 2019). The next section explores these arguments. 


\section{Mechanism 2: Multiplicative relational reasoning}

In contrast to decimals, fractions are inherently a relational expression (DeWolf \& Holyoak, 2014; Matthews \& Ellis, 2018; Thompson \& Saldanha, 2003). For example, $3 / 4$ and 0.75 each represent the same magnitude, but $3 / 4$ also transparently denotes a multiplicative relation, a ratio, between 3 and 4. This notation may help children think about multiplicative relations, proportions, and equality in ways that support algebraic reasoning (DeWolf et al., 2015a). In particular, fractions may be helpful for introducing children to functional thinking, one of the key concepts in algebra (Kaput \& West, 1994), even if they are not formally discussed as functions. Fractional notation represents a basic function, $a / b=c$, where $a / b$ is the fraction and $\mathrm{c}$ is its unidimensional magnitude (DeWolf, et al., 2015b). As long as the multiplicative relation between $a$ and $b$ is constant, $c$ will not change even with different component inputs. Formally, $\frac{a_{i}}{b_{i}}=c$, so for any given $b_{i}, b_{i} * c=a_{i}$. Thus, $a_{i}=f\left(b_{i}\right)$. In this way, fractions help children conceive of rate-ratio (Thompson, 1994), a multiplicative relation that remains invariant as the values of the numerator and denominator change together. Fractions can help children attend both to the covariation of two or more quantities simultaneously and to the preserved multiplicative relation (Ellis, 2007; Matthews \& Ellis, 2008). Reasoning with covariation is fundamental to understanding functions (Blanton \& Kaput, 2011; Thompson \& Carlson, 2017). For example, when children generate or judge equivalent fractions (e.g., $3 / 4=6 / 8=18 / 24$ ), they may be using the same functional thinking that helps them solve the input-output tables that are frequent in beginning algebra. Students might also use algorithms learned by rote or simple additive patterns to generate equivalent fractions or solve input-output tables, but fraction notation provides at least the opportunity to notice and reason with multiplicative covariation. These multiplicative relations between whole numbers that 
are highlighted in fractions are obscured in decimal notation (e.g., 0.75). Fraction notation highlights covariation, proportionality, and equality, because each magnitude can be represented by an infinite number of pairs of quantities.

Empirical evidence supports the hypothesis that understanding of fractions as relations is especially important for algebra knowledge. DeWolf and colleagues (2015a) designed a measure of relational fractions knowledge. The fraction relation test asked children to think about multiplicative relations (e.g., Which expression shows a way to find half a number, $n$ ?), inverse relations (i.e., If $n$ increases in value, then $1 / n \ldots$ ), equivalence relations (e.g., Which fraction is equal to 8/12?), and part-to-part and partto-whole ratio relations (Fig. 3). This test of fraction relations was uniquely predictive of $7^{\text {th }}$ graders' algebra scores, even when controlling for other types of fraction and decimal knowledge (DeWolf et al., 2015a). A follow-up study (DeWolf et al., 2016) randomly assigned people to either practice flexibly thinking about part-to-part or partto-whole ratios (see Fig. 3b) or to a control condition asking about algebraic procedures with fractions. The authors hypothesized that fraction relations are important for thinking about algebraic relations with unknowns, especially with proportions (e.g., "There are 5 bananas for every 2 apples. If we have 10 bananas, how many apples do we have?"). Indeed, in both $7^{\text {th }}$ graders and adults, the group that practiced relational reasoning performed better on subsequent algebra equation construction task than thinking about algebraic procedures with fractions (DeWolf et al., 2016). This manipulation is a clear example of how we can test fractions-to-algebra mechanisms. It is direct evidence that thinking about fractions as ratios can help students symbolize algebraic relations. [Figure 3 near here.] 


\section{Mechanism 3: Flexibly viewing process-object duality of math symbols}

To this point, I have reviewed arguments that the mechanism linking fractions to algebra lies in viewing fractions either as holistic numbers (i.e., magnitudes) or as relational expressions. Many researchers suggest that fractions are important for algebra precisely because they give learners an opportunity to think both ways simultaneously. These scholars emphasize the process-object duality of mathematical symbols. That is, the same mathematical concept or representation can sometimes be interpreted as a computational process and other times as an abstract object (Gray \& Tall, 1994; Sfard \& Linchevski, 1994; Sfard, 1991). Sfard (1991) also refers to this duality as thinking operationally (i.e., viewing as process) versus structurally (i.e., viewing as object). For example, an operational interpretation of the algebraic expression $3(x+5)+1$ would treat the expression as a process of computational steps, whereas a structural interpretation might treat the expression as an object like a number. Some mathematical symbols more easily afford one interpretation or the other. In $3+4=7$, it is easiest to view "7" as an object and " $3+4$ " as a process. However, the two meanings are inherently conjoined; in some cases, it is helpful to be able to treat $3+4$ as an object or to decompose 7 into a process. Indeed, the equal sign in this example helps us see the reversibility of viewing the same symbols as both process and object. Similarly, it is sometimes helpful to view $5 / 8$ as a ratio (or multiplicative relation) between 5 and 8 and at other times helpful to view $5 / 8$ as the resultant magnitude of 0.625 .

Algebra requires students to treat more and more complex mathematical symbols as objects. Whereas whole number arithmetic uses mathematical objects like "7" and "42", algebra uses such abstract mathematical objects as $-\frac{5}{9}, 3 x$, or $\frac{8 x^{2}}{x+4}$. Each of these objects is the result of processes of arithmetic operations and transformations, but algebraic problem solving requires students to shift focus away from the processes 
and towards the resultant object. Sfard and Linchevski (1994) argue that this process of reification, "to envision the result of processes as permanent entities in their own right" (p. 194), is foundational to all mathematical progress.

Fractions may provide an important opportunity to practice reifying more complex mathematical objects before learning algebra. Indeed, DeWolf et al. (2015b) suggest that fractions are an important prerequisite for advanced math because they introduce children to multidimensional numbers. Unlike the unidimensional representation of magnitude in decimals, fractions inherently, explicitly represent both the relational process and its resultant magnitude. This two-dimensional, numeratordenominator, structure of fractions is difficult for many children to grasp (DeWolf et al., 2014; Ni \& Zhou, 2005). Children who have a good grasp of the process-object duality of fraction symbols may be better prepared to view algebra structurally. If children can simultaneously view fractions as relation and magnitude, they may be better able to move flexibly back and forth between algebraic expressions as processes and as objects resulting from those processes.

A teaching experiment supports the hypothesis that fractions knowledge influences algebra knowledge through understanding of process-object duality. Using a series of seven learning activities with ninth-grade Algebra I students, Peck and Matassa (2016) showed that helping students understand the connections between fractions and division deepened their understanding of algebraic problem solving with proportions. They focused on helping students understand the fractions-as-quotient subconstruct of rational number (Kieren, 1976), which is the idea that a fraction can simultaneously represent a division problem and its result. The fractions-as-quotient subconstruct reflects the process-object duality of fraction symbols. Children's difficulty with this subconstruct is evidenced by their failure to solve division problems with non-integer 
solutions (e.g., $3 \div 12$ ). Peck and Matassa (2016) helped children construct an understanding that fractions can represent quotients (e.g., $3 \div 12=\frac{3}{12}$ ) through activities about fair-sharing and unit rates (e.g., 8 people shared 7 sub sandwiches equally. How much of a sandwich did each person get?). This understanding supported their thinking about algebraic problem solving with proportions (e.g. 4 pizzas can feed 7 people; _ pizzas can feed 1 person?) and to some extent with reasoning about slope and linear relationships (e.g., when shown a graph of the relation between total cost of a car repair (y) and hours of labor (x), can you predict the cost of a 9-hour repair?). The authors also hypothesize that an understanding of fraction-as-quotient should facilitate understanding of division with complex components as seen in algebraic notation (e.g.,

$\left.\frac{8 x^{2}}{x+4}\right)$. Although Peck and Matassa (2016) did not measure changes in the students' algebra grades or test scores after participating in their fraction-as-quotient activities, the changes in student thinking that they document likely supported students' developing algebra knowledge.

\section{Mechanism 4: Interiorization of multiplicative schemes}

One mechanism which has been theorized by math education researchers but largely ignored by psychologists is that children with strong fractions knowledge are more likely to interiorize multiplicative schemes that are helpful for algebra. The language of "schemes" and "interiorizing" comes from the dominant theory of learning in the field of math education: constructivism. Math education's constructivist perspective, rooted in Piaget \& Duckworth (1970) and von Glasersfeld (1995), assumes that math must be constructed inside the learner's mind. Although there are many variations of constructivism, these approaches generally posit that learners have cognitive schemes that help them interpret and interact with the world. 
Hackenberg and colleagues (Hackenberg, 2007; 2010; 2013; Hackenberg \& Lee, 2011; 2015; 2016; Norton \& Hackenberg, 2010) have written extensively on the connection between fractions and algebra from a constructivist perspective. A full discussion of constructivist theory and terminology is beyond the scope of this paper, but a few definitions are necessary in order to understand Hackenberg's proposed fractions-to-algebra mechanism. Schemes (von Glasersfeld, 1995) are composed of specific operations, or mental actions (Hackenberg 2010). Operations that are important for fractions include partitioning, iterating, splitting, units coordination, and disembedding (Steffe \& Olive, 2010). Partitioning involves dividing a unit into equalsized parts, and iterating involves repeating one of these parts to construct a larger amount. Splitting is a composite operation involving both partitioning and iterating simultaneously. Units coordination is imagining multiplicative structures that are a unit of units (e.g., to solve $4 \times 5$ one might imagine 4 units, each of which contains 5 units; Hackenberg, 2007), and disembedding involves "taking a part out of a whole unit without mentally destroying the whole" (Hackenberg, 2010, p. 385). For example, a child might construct $3 / 5$ of a whole by partitioning the whole into 5 equal parts, disembedding one part, and iterating that part 3 times. Schemes made up of these operations are modified gradually over time, as students are confronted with new situations and must reorganize existing schemes or create new schemes to achieve their intended result. When a scheme is so familiar that the person can take its result as given without actually engaging in the scheme, this scheme is said to be interiorized. Hackenberg (2010) calls interiorized schemes concepts.

Using months-long teaching experiments and in-depth interviews with students in middle and high school, Hackenberg and colleagues have charted the development of fraction schemes. Table 4 shows examples of problems used to elicit student's fractional 
thinking. Using tasks like these, Hackenberg and other math education researchers have outlined a learning progression of increasingly advanced fraction schemes (Hackenberg \& Tillema, 2009; Steffe, 1992; Steffe \& Olive, 2010; Wilkins \& Norton, 2011). Early fraction schemes involve only partitioning, whereas later schemes use the operations of disembedding, iterating, and splitting (Hackenberg, 2013; Norton \& Wilkins, 2010).

Children who are stuck in earlier fraction schemes are likely to struggle as they begin to learn algebra, because many of the mental actions used in fraction reasoning are needed for algebraic problem solving and equation writing (Hackenberg, 2013; Hackenberg \& Lee, 2015; 2016). [Table 4 near here.]

Hackenberg $(2007 ; 2013)$ and colleagues (2017) have highlighted two operations in fraction schemes as being especially important for algebra: units coordination and disembedding. Specifically, children's ability to coordinate three levels of units - a unit of composite units - is important for understanding improper fractions (Hackenberg, 2007) and writing algebraic equations (Hackenberg, 2013; Hackenberg et al. 2017; Hackenberg \& Lee, 2015; Olive \& Caglayan, 2008). Coordinating three levels of units is possible in whole number reasoning as well - for example, as shown in Figure 4a, 24 can be considered a composite unit containing eight units, each of which is a unit containing three units of 1 . This complex units coordination is essential for thinking about improper fractions - as shown in Figure 4b, a candy bar that is $9 / 7$ of the whole can be considered a unit of $9 / 7$, which is a composite unit containing 9 units, each of which is a unit containing $1 / 7$ of a whole.

\section{[Figure 4 near here].}

As adults, we might easily anticipate or take for granted the coordination of units - that the bar in Figure 4a can be considered twenty-four 1's, four 6's, six 4's, eight 3's, or three 8's. Developing this anticipatory thinking gives students flexibility 
and allows them to build more complex structures and relations. First, children learn to coordinate units in activity, as seen in Figure 5 (Hackenberg, 2010; Stevens et al., 2020). A child who can coordinate three levels of units in activity cannot hold all three levels of units in mind simultaneously; they cannot view the piece of pie in Figure 5 flexibly as made up of 2 parts, each of which is $1 / 5$ of an unseen whole. Eventually, with practice, children interiorize three levels of units and can foresee the results of mental actions prior to activity (Hackenberg, 2010). Middle school students who have not yet interiorized this unit-of-units-of-units multiplicative structure have difficulty writing algebraic equations to model problems like those seen in Table 4 or Figure 5 (Hackenberg \& Lee, 2015). In contrast, students who had interiorized three-level multiplicative structures were easily able to produce an equation (e.g., $S=5 \times R$ for Table 4, Problem 2) and recognize the reversibility of the multiplicative relation (e.g., $R$ $=S \div 5$ ). [Figure 5 near here.]

Difficulty disembedding a fractional part from the whole without mentally destroying the whole can also hinder algebraic problem solving, especially equation writing (Hackenberg, 2013). An example from Henry, a $7^{\text {th }}$ grade student interviewed by Hackenberg (2013), illustrates the importance of disembedding. Henry was presented with an algebra problem in which "Stephen's iPod cord is 5 times as long as the unknown length of Rebecca's cord". To symbolize this situation, Henry wrote the equation “ $R$ x 4 = Stephen's cord”. Hackenberg (2013) interprets Henry's equation and explanation as evidence that "Henry appeared to think of Stephen's length as five parts, one of which had to be Rebecca's, leaving Stephen with only 4 parts.” (p. 553). Henry was not able to consider Rebecca's cord length simultaneously as part of the whole and as separate from the whole. This example illustrates that disembedding is essential for 
understanding multiplicative relations with unknowns (e.g., 5 times as long as $x$ ) instead of incorrectly interpreting these relations additively (e.g., 4 more than $x$ ).

In many studies, Hackenberg and others (Byerly, 2019; Hackenberg, 2010; 2013; Hackenberg et al., 2017; Hackenberg \& Lee, 2015; Kaput \& West, 1994; Nabors, 2003; Olive \& Çaglayan, 2008; Thompson \& Saldhana, 2003) argue that advanced multiplicative concepts - interiorized fraction schemes - support algebraic reasoning. From a constructivist perspective, though, multiplicative concepts are not viewed as a mechanism connecting two distinct bodies of knowledge (i.e., fractions and algebra). Rather, all mathematics is constructed gradually and continuously in the minds of students as they act to reach their goals. Nevertheless, Hackenberg and colleagues' ideas and methods offer an important perspective about the mechanisms driving the fractions-to-algebra path. Students who perform better on psychological tests of fractions knowledge may be more likely to have advanced multiplicative schemes, which lead to better algebra knowledge. Therefore, I consider multiplicative concepts as a mechanism through which fractions knowledge may influence algebra knowledge.

To this point, I have discussed four proposed mechanisms in detail: number system understanding, multiplicative relational reasoning, process-object flexibility, and interiorization of multiplicative schemes. Each of these mechanisms focuses most on connecting conceptual knowledge of fractions to algebraic reasoning and problem solving. However, other scholars have argued that arithmetic skill and procedural fluency with fractions are key preparation for algebra. Additionally, students' fractions knowledge may influence the socioemotional context of their math learning, thereby influencing their algebra knowledge. In the following paragraphs, I will discuss two final mechanisms and identify challenges in establishing evidence for causal mediation from fractions to algebra. 


\section{Mechanism 5: Procedural fluency}

Procedural fluency is the ability to quickly and accurately calculate solutions to fraction arithmetic problems. As reviewed in the first section, many scholars have found an association between procedural fluency with fraction operations and algebra knowledge (Booth et al., 2014a; Hurst \& Cordes, 2018b; Liang et al., 2018; Powell et al., 2019; Siegler et al., 2012). This association holds even when the algebra test does not include any equations with fractions (Hurst \& Cordes, 2018a; 2018b). A connection between procedural fraction calculation skill and algebra is not easily explained by any of the mechanisms reviewed to this point. Instead, scholars have proposed an “arithmetic-to-algebra pathway" (Blanton et al., 2018; Pillay et al., 1998; Powell et al., 2019; Wu, 2001) that might help explain the association between fraction procedural skill and algebra knowledge.

Children with fluent fraction arithmetic skills are less likely to make calculation errors in algebraic problem solving (e.g., Hurst \& Cordes, 2018a) and may be less likely to mis-apply fraction ideas when the numerator and denominator get more complex. Algebra I students frequently make errors due to misapplication of fraction arithmetic concepts and procedures (Booth et al., 2014b). These errors include combining the denominator and numerator incorrectly (e.g., $\left.\frac{5}{(2 d-4)}=2 d-20\right)$, misinterpreting the fraction bar as a multiplication symbol (e.g., $\left.\frac{-1}{15}=-15\right)$, and using subtraction instead of multiplication to cancel out the denominator (e.g., subtracting 4 from both sides in $\left.\frac{9-6 x}{4}=5\right)$. As seen in these examples, division in algebraic equations is almost always denoted by the fraction bar, which can be challenging for students to reason with if they do not have a good grasp of how to operate with fractions (Peck \& Matassa, 2016). These common errors indicate that students' difficulty in algebra may stem in part from 
their lack of understanding of fraction operations and the fraction-as-quotient subconstruct (Kieren, 1976).

As children progress from whole number arithmetic to fraction arithmetic to algebra, symbolic notation becomes more complex, generalized, and abstract. Fraction arithmetic may be particularly helpful for algebra learning if it helps children see the fundamental properties and relations of arithmetic expressed in symbolic notation (Empson et al., 2011). A focus on generalizable properties and abstract representations of these properties may facilitate students' understanding of abstract algebraic notation and generalized mathematical proofs (Blanton et al., 2018; Empson, et al., 2011; Wu, 2001). For example, learning activities with visual representations of unit fractions can eventually help children see the pattern that $m \times \frac{1}{n}=\frac{m}{n}$ (Empson et al., 2011). Gradually introducing students to algebraic notation to represent these patterns may ease the transition to algebra. For example, children could be introduced to a formula for fraction addition $\left(\frac{a}{b}+\frac{c}{d}=\frac{a d+b c}{b d}\right)$ and eventually learn that this formula is true for any $a, b, c$, and $d$, be they integers, fractions, or polynomials (Wu, 2001). Indeed, the introduction of algebraic notation in early elementary school to teach fundamental properties of whole number (e.g., $a+b=b+a)$ is helpful for success in later algebra classes (e.g., Blanton et al., 2019). If explicit instruction connecting fraction arithmetic algorithms to algebraic notation was more widespread, the association between fractions knowledge and algebra knowledge might be even stronger.

Another way that fraction arithmetic may support algebra is by training children's perceptual systems. Although mathematics is typically considered to progress from concrete to abstract, students increasingly rely on perceptual processes in math problem solving (Braithwaite et al., 2016; Goldstone et al., 2017; Jiang et al., 2014; Landy et al., 2014; Landy \& Goldstone, 2009; Schneider et al., 2012). As students learn 
to efficiently perform arithmetic operations, including fraction operations, their visual systems learn to quickly extract patterns from problem syntax. For example, they learn to correctly parse expressions into visual groups (e.g., $4+6 \times 3-2$ as $4+$

$(6 \times 3)-2)$ and to prioritize expressions which are easier to evaluate (e.g., $18-8$ in $44+18-8)$.

Students with more fluent fraction arithmetic skills may become better at these perceptual "tricks", which are essential for mastery of algebra. Children who can add or multiply fractions efficiently may solve more fraction arithmetic problems over the elementary school years than their peers, as they finish more problems in homework, class work, and tests given equal amounts of time. Over time, fluent students may thus accumulate more opportunities to practice noticing structure in symbolic expressions, which may provide them with an advantage when they start learning algebra. Eyetracking studies and experimental paradigms from cognitive psychology have shown that algebra learners develop rapid, automatic perception of the hierarchical structure in equations (Marghetis et al., 2016; Schneider et al., 2012). These "Rigged Up Perception-Action Systems" (Goldstone et al., 2017) may be the tools that allow our brains, which did not evolve to understand formal mathematics, to engage in algebraic reasoning. Thus, another way through which fraction arithmetic knowledge supports later algebra learning may be that it helps retrain students' visual systems to perceive structure in equations.

I named this mechanism procedural fluency, but children who quickly apply algorithmic procedures to fraction operations without conceptual understanding of those procedures may be less likely to benefit from symbolic fluency. Students who have a deeper understanding of the meaning and structure of fraction algorithms are more likely to be able to generalize these procedures to algebraic problem solving than 
students who apply procedures by rote (Brown \& Quinn, 2007; Empson et al., 2011). Many students simply follow memorized steps when calculating with fractions (e.g., “invert-and-multiply" for division by a fraction) (e.g., Hecht \& Vagi, 2012). If students can solve basic fraction operations quickly with rote procedures, they may seek these same kinds of conceptually shallow algorithms when they approach algebraic equations (Brown \& Quinn, 2007). Importantly, as mathematics gets increasingly complex, students who perform calculations without conceptual understanding may also become frustrated and disengaged by the increasing number of seemingly meaningless rules (Wu, 2001).

\section{Mechanism 6: Motivation}

Fraction and algebra learning do not happen in a vacuum; students' approaches to math learning are influenced by their experiences, circumstances, and attitudes. Motivation is one of the strongest predictors of math achievement besides prior achievement (Cleary \& Chen, 2009; Froiland \& Worrell, 2016; Gottfried, et al., 2013; Kriegbaum et al., 2015). The expectancy-value theory of motivation (Wigfield \& Eccles, 2000) argues that math motivation and achievement are highest among students who believe they will succeed in math and who perceive math as valuable. Thus, students with low confidence in their ability to succeed in math, or who perceive math to have a low value or low utility for their lives, are less likely to engage in math class, persist when math problems become difficult, and attempt more rigorous problems or courses (Froiland \& Davison, 2016; Gottfried et al., 2013; Jang et al., 2012).

Children who struggle with fractions may experience diminished motivation to learn math, which may lead them to learn less from subsequent instruction. Fractions are notoriously difficult for children (Siegler \& Pyke, 2013) and may be the first time they encounter a barrier in math that seems impassable. Especially for children with a 
fixed mindset, this failure or struggle may lead to self-labeling (e.g., "I am not a math person") and disengagement with math (Boaler \& Greeno, 2000; Dweck, 2006). Indeed, children and adults with all levels of math ability have more negative attitudes about fractions than whole numbers (Sidney et al., 2019). Given that fractions are a major topic throughout later elementary and middle school, these negative attitudes about fractions may bleed over into children's overall math attitudes, including influencing their attitudes and beliefs about algebra. Children with low fraction ability may be especially harmed by the onset of these negative attitudes; lower expectations of one's own performance is tied to valuing math less and lower motivation to learn math (Wigfield \& Eccles, 2002). Motivation has not yet been proposed or tested, by psychologists or math education researchers, as a mechanism through which fractions knowledge may influence algebra. Because of its strong influence on engagement and achievement, the socioemotional context of math learning should receive more attention in future studies of fractions-to-algebra.

\section{Questioning assumptions: Causal directionality}

To this point, I have considered six plausible mechanisms through which fractions knowledge may influence algebra knowledge. These six mechanisms are neither exclusive nor independent; it is likely that fractions influence algebra through some combination of these mechanisms. Thus far, I have framed each of these mechanisms as potential causal mediators: having better fractions knowledge helps students with relational reasoning, interiorization of multiplicative schemes, flexible process-object interpretations of symbols, etc. In turn, these mediators are hypothesized to help students with algebra learning. Each of these mechanisms addresses the question "Why might better fractions knowledge help children with algebra?", but there is not clear evidence that they are causal mediators. Instead, some of these proposed 
mechanisms may precede or develop bidirectionally with fractions knowledge. Others may not be mechanisms at all, but may merely be aspects of fractions knowledge. Before moving on to build a conceptual model of the fractions-to-algebra pathway, it is important to consider whether the assumptions I have been making about causal directionality are reasonable. [Figure 6 near here.]

A mediated relation has three paths (Figure 6): improvements in fractions knowledge should cause improvements in the mediator (path $A$ ), improvements in the mediator should cause improvements in algebra knowledge (path $B$ ), and these paths together should explain a significant amount of the direct relationship between fractions knowledge and algebra knowledge (path $C$ ). Given current evidence, the assumed directionality of path $A$ is difficult to uphold for the current set of mechanisms. Students bring many characteristics, experiences, and skills to fractions instruction, so it can be difficult to show that the mediator is a result of fractions knowledge rather than a predictor.

Any of the proposed mechanisms that have been discussed could plausibly precede fractions knowledge. Individual differences in each of the proposed mechanisms exist prior to fractions instruction: some children have a deeper understanding of the number system before learning rational numbers, some children have better relational reasoning and analogical skills in math and other domains before fraction learning, some children approach fraction learning with lower motivation than other children, etc. Any investigation of fractions-to-algebra mechanisms must account for this reverse causality. For example, children who have a better understanding of the number system with whole number magnitudes and operations are likely to learn more from fractions instruction (Mechanism $1 \rightarrow$ Fractions Knowledge; Bailey et al., 2014), and learning rational numbers also facilitates deeper and more generalized 
understanding of number (Fractions Knowledge $\rightarrow$ Mechanism 1; Christou \& Vosniadou, 2012).

Additionally, many of the proposed mechanisms could develop concurrently with fractions knowledge. For example, as students gain flexibility in thinking about math symbols as both process and object (Mechanism 3), they will likely improve in their understanding of both algebraic expressions and fractions. As students interiorize more advanced multiplicative schemes (Mechanism 4) their reasoning skills are likely to improve both for fractions and for algebra. Similarly, if students' motivation (Mechanism 6) decreases after experiencing difficulty with fractions, this is likely to harm subsequent learning in both fractions and algebra. This intertwining of fractions and algebra knowledge makes it difficult to establish temporal ordering and causal directionality in empirical study. In future studies, longitudinal designs can be used with statistical tools such as cross-lagged structural equation models to clarify the direction of influence (e.g., Bailey et al., 2017).

Importantly, fractions knowledge and algebra knowledge are not static constructs that are "achieved" in a short amount of time. Rather, fraction and algebra understanding both develop gradually over the course of many years, and both have roots in math learning years before they are formally introduced in schools. For example, "number sense" exercises in early elementary school help children learn that numbers can be constructed through different combinations of sets (e.g., $8=2+6=$ $2+3+3=10-2$; and eventually $8=2 \times 4=32 \div 4=2^{3}$ ). This basic composition and decomposition of numbers may help children form foundational understandings of equality, process-object duality, and relations among quantities that are essential for both fractions and algebra knowledge (MacDonald \& Wilkins, 2019; Tzur, 2019; Wilkins \& Norton, 2011). Fractions knowledge also continues to develop for years after 
formal fractions instruction begins, even as students learn algebra. Indeed, math education can be conceived of as a "spiral curriculum" (Bruner, 1960; Harden \& Stamper, 1999), in which the learning of new concepts can continue to deepen and strengthen understanding of more basic mathematical ideas. To unwrap this spiral into distinct pieces of knowledge classified as "fractions knowledge" and "algebra knowledge" is daunting. Yet, this precision is necessary if we are to more fully understand how to help struggling students understand algebra.

Finally, some of the proposed mechanisms may be more accurately considered a subset of fractions knowledge rather than a result of fractions knowledge. For example, I have suggested that the interiorization of multiplicative schemes may be a mechanism, but in multiple studies these schemes are used to characterize fractions knowledge itself (Hackenberg, 2013; Hackenberg \& Lee, 2015; Norton \& Hackenberg, 2010; Stevens et al., 2020). Similarly, arithmetic fluency, which I consider a potential mediator between fractions and algebra knowledge, has been considered an aspect of fractions knowledge in many psychological studies (DeWolf et al., 2015a; Hurst \& Cordes, 2018a; 2018b; Powell et al., 2019; Siegler et al., 2012). As discussed earlier, fractions knowledge is a broad and multifaceted construct. If there is a specific piece of fractions knowledge that is particularly helpful for algebra, such as schemes or fluency, it is reasonable to consider it a mediator between the broad constructs of fractions knowledge and algebra knowledge. Indeed, identifying relations between specific aspects of each type of knowledge is essential to improve the precision of the fractions-to-algebra pathway.

\section{A call for interdisciplinary collaboration to improve fractions-algebra research}

Psychologists and math education researchers agree that it is important to explore foundations of algebra knowledge, recognizing that students' success in algebra 
classes is important for their life chances. However, these explorations have remained mostly siloed by discipline, using different methodologies and starting from different epistemological and theoretical positions. Despite this profound disconnect, fractions knowledge has emerged in both disciplines as an especially important foundation for algebra. To understand this connection and leverage it to improve education, we cannot remain isolated within the boundaries of our own disciplines. We need interdisciplinary collaboration, drawing on the strengths and expertise of both math education researchers and psychologists.

\section{Different theoretical foundations}

Fractions-to-algebra research has been shaped by distinct theories of knowledge and learning from math education and psychology. Most math education research in this area explicitly situates itself as constructivist (von Glasersfeld, 1995; Piaget \&

Duckworth, 1970). Constructivism refers to a wide-ranging set of theories about learning and knowledge, but broadly constructivists assume that knowledge is constructed in the mind of the learner. Thus, constructivist assessments of knowledge often involve detailed interviews or case studies focused on understanding how students build knowledge of mathematics, highlighting their phenomenological experiences and ways of thinking and sense-making.

Psychology, on the other hand, approaches fractions-to-algebra research with learning theories that are rarely made explicit. Much of the psychological literature in this area seems to be influenced by information-processing theories of learning (e.g., Kail \& Bisanz, 1992). Like constructivism, information-processing refers to a range of related learning theories. Generally, these approaches assume that the human mind processes information in ways similar to a computer: cognition is a combination of foundational processes like attention, perception, working memory, and long-term 
storage. From a traditional information-processing perspective (e.g., Atkinson \& Shiffrin, 1968), learning in math - or any domain - occurs by taking in, manipulating, storing, and retrieving information. These traditional theories have been expanded and modified in many ways, but they continue to influence cognitive development research in psychology. Thus, outcomes in psychological fractions-to-algebra studies tend to be more focused on inputs and outputs in information processing (e.g., accuracy, response times, etc.) than on characterizing individual students' thinking.

\section{Complementary strengths: Causal inference, measurement, and constructs}

The two disciplines contribute to different pieces of the puzzle. Psychologists use replicable, quantitative tests and powerful statistical techniques that help isolate the causal effects of fractions knowledge on algebra knowledge amongst other control variables. Statistical methods also measure and account for uncertainty on multiple levels - uncertainty due to random variability in the sample and in the items used to measure a construct, allowing psychologists to quantitatively measure the likelihood that a result would have occurred by chance alone. With relatively large sample sizes and rigorous statistical methods, psychological studies aim to make generalizable claims about how learning happens for the larger population. These methods produce effect size estimates - numerical estimates of how much a fraction intervention or policy change could improve a student's algebra score - a powerful tool to earn the attention of educational policymakers.

The methods of the reviewed psychological studies allow researchers to conclude that the relation between fractions knowledge and algebra knowledge is not just due to better whole number knowledge, better general math skills, better literacy or language skills, more advantaged background, or intelligence (Booth \& Newton, 2012; Booth et al., 2014a; DeWolf et al., 2015a; Hurst \& Cordes 2018a; Liang et al., 2018; 
Powell et al., 2019; Siegler et al., 2012). They show that the correlation is present in children who have just started to learn fractions ( $4^{\text {th }}$ graders - Hurst \& Cordes, 2018a), middle school students who have had years of fractions instruction but no algebra class yet (Booth \& Newton, 2012; DeWolf et al., 2015a; Liang et al, 2018), current Algebra I students (Booth et al., 2014a), and adults who have may not have taken a math class in years (Hurst \& Cordes, 2018b; Powell et al., 2019). These studies also demonstrate that the relation can be seen prospectively: fractions knowledge predicts algebra knowledge 1 year (Liang et al., 2018) to 6 years later (Siegler et al., 2012), and fractions knowledge at an algebra unit's start predicts learning gains during that unit (Booth et al., 2014a).

Nevertheless, there are many weaknesses in the way psychology has contributed to this research question. Most fundamentally, psychologists have spent too little time defining the constructs of fractions knowledge and algebra knowledge that they purport to measure, as I reviewed in the first section of this paper. Minimally, scholars from psychology seem to agree that fraction magnitude and fraction arithmetic are important subdomains of fractions knowledge (see Table 1). However, math education work suggests that there are many other important aspects of fractions knowledge, which psychology has largely ignored (e.g., Steffe and Olive's (2010) schemes, Kieren's (1980) subconstructs, etc.). In measuring algebra, psychologists have often abandoned definitions altogether, preferring to use omnibus tests or problems from Algebra I textbooks (see Table 2). My exploration of the plausible mechanisms connecting fractions to algebra suggests that, without more clearly defining and operationalizing both types of knowledge, it will be difficult to make progress towards understanding how and why they are connected.

Future studies could benefit from combining psychological measures with math education's robust definitions and theoretical work on fractions and algebra knowledge. 
For example, if more advanced fraction schemes are important for algebra knowledge (as Mechanism 3 suggests), then tests of the fraction-algebra connection ought to include measurement of key components of fractions schemes (partitioning, disembedding, units coordination, etc.). However, it remains unclear whether common psychological tests like fraction number line estimation and magnitude comparison capture this aspect of fractions knowledge. Similarly, more specific definitions of algebra would help clarify the fractions-algebra association. For example, measuring the core aspects of algebra knowledge separately might reveal that some aspects of fractions knowledge are particularly helpful for one core area of algebra (e.g., functional thinking) whereas other aspects of fractions knowledge are uniquely helpful for another area (e.g., equivalence). Existing psychological studies are unable to test these kinds of nuanced relations.

Additionally, the typical ways that psychologists measure fractions knowledge (number line estimation, magnitude comparison, timed arithmetic tests, multiple-choice tests, etc.) are less sensitive to nuances of understanding than the in-depth interviews and multi-session teaching experiments used in math education research. Because of their focus on students' answers instead of their reasoning, psychological tasks tend to collapse important differences between students into a single metric. A simple fraction comparison task, for example, is unlikely to discriminate between students who can flexibly view math symbols as process and object and students who rigidly view each symbol in one way or the other. Estimation of fractions on the number line, or even a written fraction concepts test (e.g., Powell et al., 2018), will not necessarily show which students have interiorized multiplicative schemes. On these tasks, children can use many strategies, some of which would show deeper understanding than others, but none of which is measured directly by the assessment. [Figure 7 near here.] 
For example, as shown in Figure 7, a typical psychology-style fraction item may ask where $5 / 8$ goes on a line from $0-1$. Two students could place $5 / 8$ in the same position, thus receiving indistinguishable scores, with vastly different understandings of the fraction 5/8. Student A might only be able to conceive of 5/8 as 5 parts of an 8 -part whole, whereas Student B can flexibly interpret 5/8 in many ways (as five iterations of $1 / 8$, as a measurement length that is $5 / 8$ as long as the whole line, as a distance slightly greater than $1 / 2$, etc.). These differences in fractions knowledge would not be captured by a typical number line estimation task; they would not be evident unless the test requires a child to verbalize (or write) their thinking. Indeed, a child could score well on almost every measure used by psychologists to assess fractions knowledge without deeply understanding multiplicative relations. The coarseness of measurement seems to be a major problem for the fractions-to-algebra pathway as described by psychologists. Of course, psychological studies have nevertheless found a strong relation between fractions and algebra - thus, whatever psychologists are capturing with fraction measures, it does seem to be important for algebra.

Perhaps fractions are important for algebra in multiple ways, some of which are captured by traditional psychological measurements and others that can only be captured with more detailed assessments typical of math education research. In order to test this possibility and determine which causal pathways are strongest, studies would ideally include both styles of measurement. Some psychology studies attempt to gauge deeper understanding by asking students to report their strategies (e.g., Luwel et al., 2019) or give written explanations to support their answer (e.g., Fyfe et al., 2018), but to date none of these methods have been used to evaluate fraction understanding as it relates to algebra knowledge. In math education, children's fraction schemes have begun to be measured through written assessments instead of interviews alone (Wilkins 
et al., 2013; Norton et al., 2015), but these methods have not been used to investigate the fraction-algebra relation. As we seek to refine definitions and measurements of fractions and algebra knowledge, we should draw upon the expertise and designs of both psychological studies and math education research.

\section{Converging evidence: An ecumenical project}

This review of the scope and breadth of research on the fractions-algebra association shows that researchers are still near the beginning of understanding this important connection. Many types of evidence from across psychology and math education have converged upon the conclusion that fractions are especially important for algebra learning: large-scale correlational studies at a single point in time (e.g., DeWolf et al 2015a) or across time (Booth et al., 2014a; Liang et al., 2018; Siegler, 2012), in-depth analyses of connections between mathematical concepts (e.g., Empson et al., 2011), and detailed interviews of student thinking over multiple sessions of carefully-designed learning activities (e.g., Hackenberg \& Lee, 2015). This evidence also aligns with recommendations from experts (NGA, 2010; NMAP, 2008).

Psychologists and math education researchers have been pursuing this question largely in parallel, but their joint expertise is needed to specify the broad fractionsalgebra association into more nuanced relations and a clearer fractions-to-algebra pathway. The questions I started with have begun to be addressed, but their answers are far from clear. In my review of psychology's quantitative studies of the association in Section 1, I suggested that the strength of causal evidence is limited by idiosyncratic measurement, limited longitudinal research, and imprecise definitions of both types of knowledge. Math education research has identified core subconstructs of fractions and algebra and measured them through in-depth interviews, but these qualitative measures cannot be used to statistically test the path from fractions to algebra. Both fields suggest 
that better fractions knowledge leads to better algebra knowledge, but the current evidence is insufficient to support or explain that causal claim. We need more precise definitions, measurement, and designs at every point of the hypothesized pathway.

From both disciplines, many explanations have been proposed for why children with better fractions knowledge tend to have better algebra knowledge. As I reviewed in Section 2, children's view of the fraction symbol may influence their view of algebra symbols, procedural skills with fractions may support algebraic problem solving, and fractions knowledge may influence students' motivation and engagement in later math instruction. Research is only now starting to investigate these hypotheses, and the results will have important implications for building theory and practice.

In the final section of the paper, I will address the broader question that motivated this review. Given what we know from psychology and math education research on the fractions-to-algebra association, how can future research designs take advantage of the expertise from both fields to test these plausible explanations?

\section{An integrative conceptual model from fractions to algebra}

This review has illustrated that the connection between fractions and algebra knowledge is undeniably complex. Figure 8 presents a schematic diagram of the potential fractions-to-algebra pathways as reviewed above. To untangle these pathways, we need to build interdisciplinary teams of researchers who contribute different expertise and theoretical perspectives to a shared aim. The combination of psychology's replicable quantitative measures and statistical modeling, with math education's deep appreciation for mathematical constructs and student thinking, will lead to new insights about how and why fractions and algebra knowledge are related. As research on the fractions-to-algebra pathway continues, these collaborative teams should ensure (a) that all constructs are clearly defined and measured, (b) that rigorous research designs 
account for alternative explanations for the relationship, and (c) that temporal ordering is established wherever possible to clarify causal directionality of mechanisms. [Figure

\section{8 near here.]}

First, fractions knowledge and algebra knowledge must be clearly defined. If every researcher provides clear working definitions of fractions knowledge and algebra knowledge, other scholars can build upon, critique, or accept these definitions. With such broad constructs, there will certainly be heterogeneity in how scholars conceptualize and define both types of knowledge. But as groups of scholars move towards shared, explicit definitions, these definitions can guide the construction of theoretically-grounded measures of both types of knowledge. As measures of fractions and algebra knowledge are refined, researchers should consider not just "correct" answers but also how students' mathematical thinking generated the answers. Precise definitions and measurement are also needed for each of the mechanisms that are being tested. This review highlighted and described six plausible mechanisms, but more attention to operationalization of these mechanisms is needed.

Second, research designs need to rule out, or account for, alternative explanations. Psychological studies have already established that the fractions-toalgebra relation persists when controlling for many covariates. As studies begin to systematically test mechanisms, it will also be important to control for prior abilities related to these mechanisms, to isolate the causal pathway from fractions knowledge to the mediator. For example, as shown in Figure 6, a study testing whether procedural fluency mediates the relation from fractions knowledge to algebra knowledge should ideally include a control measure of procedural fluency with whole numbers at an earlier time point than the test of fractions knowledge. This longitudinal ordering of measures may be costly or impractical, so it may be most prudent to identify which 
mechanisms seem most important in single-session correlational studies first. Indeed, a variable cannot be a mediator unless it is correlated with both fractions knowledge and algebra knowledge, and these correlations have yet to be established for many of the mechanisms listed in Table 3 and Figure 6. Ultimately, though, strong evidence for a mediational pathway will require longitudinal evidence, with carefully timed measurements of covariates, fractions knowledge, mechanisms, and algebra knowledge.

Finally, as mentioned earlier, the best causal evidence for a fractions-toalgebra relation will come from interventions which experimentally manipulate fractions knowledge. Ideally, interventions would be targeted at individual aspects of fractions knowledge with clear hypothesized mechanisms through which those aspects of fractions knowledge would influence algebra, although in some cases the components of fractions knowledge may be difficult or impossible to isolate. For example, Fuchs and colleagues' (2013; 2014; 2016; 2017) classroom intervention for $4^{\text {th }}$ graders focused on fraction magnitude knowledge and conceptual understanding of arithmetic procedures. The intervention successfully improved fractions knowledge in multiple samples (see Fuchs et al., 2017 for a review), but its effect on algebra knowledge remains untested. Interventions like this have powerful potential to advance our theoretical understanding of the fractions-to-algebra pathway. A well-designed longitudinal study could measure skills and background characteristics at the beginning of $4^{\text {th }}$ grade (e.g., covariates in Figure 8), fractions knowledge at the end of the $4^{\text {th }}$ grade intervention, possible mechanisms (e.g., understanding of generalized number, symbolic fluency, or metacognition) in $5^{\text {th }}$ grade, and pre-algebra or algebra knowledge in $7^{\text {th }}$ or $8^{\text {th }}$ grade. An intervention like Fuchs and colleagues' would be especially well-suited to a longitudinal investigation, given its large effect sizes in multiple studies 
(Fuchs et al., 2017). Longitudinal experimental evidence would provide the best estimate of the causal effect of fractions knowledge on algebra. Carefullydesigned longitudinal studies are also needed to test and compare possible fractions-to-algebra mechanisms.

\section{An alternative perspective: Causal or constitutive?}

Throughout this paper, I have discussed a causal pathway from fractions to algebra knowledge. I have reviewed evidence that students with better fractions knowledge tend to have better algebra knowledge, and I have discussed ways in which future research could strengthen the claim that this is a causal, directional relation. Longitudinal research from psychology has already strengthened the causal claim by establishing temporal ordering and controlling for alternative explanations. Future work could also improve clarity of measures and test mechanisms through which fractions knowledge could have a causal effect on later algebra knowledge, such as those I have proposed here. Ultimately, the goal of this line of work is to better understand whether, how, and why better fractions knowledge leads to better algebra knowledge, to inform theory and intervention. This is the perspective that most existing research, especially from psychology, has taken.

Alternatively, students with better fractions knowledge might end up with better algebra knowledge because fractions are algebra. That is, fractions may be inherently algebraic and thus fraction knowledge may be simply a foundational part of algebra knowledge. Indeed, some aspects of fraction reasoning are similar to the ways algebraic thinking has been defined, with both having an emphasis on generalizing, reasoning with mathematical structure, and thinking about functions and equality (Blanton et al., 2018; Empson et al., 2011). Indeed, Empson and colleagues (2011) argue that fraction learning and reasoning gives children practice with "the fundamental properties of 
operations and equality that form the foundations of algebra" (p. 410). For example, an understanding of equivalent fractions (e.g., $3 / 4=6 / 8=150 / 200$ ) requires children to notice and generalize the mathematical structure of the numerator-denominator relation. Similarly, students can use algebraic reasoning as they try to solve equal sharing problems with fractional solutions. For example, to share 2 pancakes equally among 3 children, a child might break down the problem by splitting each pancake in thirds in the following way (although likely without this notation): $2 \div 3=(1+1) \div 3=1 \div$ $3+1 \div 3=\frac{1}{3}+\frac{1}{3}$

From this alternative perspective, the longitudinal evidence from psychology (Booth et al., 2014a; Liang et al., 2018; Siegler et al., 2012) no longer looks like causal evidence. Instead, it merely shows that the fractions knowledge component of algebra knowledge may develop before other aspects of algebraic reasoning such as equation solving. Associations between fractions and algebra in psychology and math education research may reflect that the two types of knowledge are two sides of the same coin. This perspective suggests that both types of knowledge may influence each other, yet it would not make sense to describe their relation as "bidirectional" because the two types of knowledge are not separable.

If fractions knowledge is constitutive of algebra, then it would not make sense to talk about or test a simple, linear causal relation. However, it would still make sense to investigate the fractions-algebra association more deeply. Some ways of thinking about fractions may highlight their algebraic character, whereas other ways of thinking may lead students to see fractions as detached from algebra. For example, discussing equivalent fractions (e.g., $3 / 4=12 / 16$ ) by talking about their similarities in structure (e.g., the ratio or relationship between 3 and 4 is the same as the relationship between 12 and 16) may highlight the algebraic character of fractions. If, instead, students 
convert fractions to decimals using a calculator to decide if they are equal (e.g., $3 \div 4=$ 0.75 and $12 \div 16=0.75$ ), this may push students away from algebraic thinking with fractions. Research should consider how fractions might be used in early algebra instruction in elementary school, which has so far focused exclusively on whole numbers (see Stephens et al., 2017 for a review).

How can future work determine whether the relationship between fractions and algebra is causal or constitutive? Does fraction knowledge cause better algebra knowledge, or is fraction knowledge a component of algebra knowledge? As I have argued throughout this paper, better definition of both types of knowledge and clearer construct validity of their assessments is essential. As we more clearly articulate and measure the core aspects of fraction knowledge and algebra knowledge, the boundaries of their constructs will also become clearer. However, empirical work alone cannot necessarily differentiate between the causal and constitutive hypotheses. Even if a statistical model shows evidence for a bidirectional causal relation between a fractions test and an algebra test, the underlying relation could still be constitutive. Therefore, it is essential that all research is grounded in theory, from the definition and measurement of the constructs to the design and analysis of the study.

\section{Future directions}

The fractions-algebra association is ripe for further exploration. This review shows that psychologists and math education researchers have separately come to the same conclusion: fractions are an important foundation for algebra. Each field has hypothesized explanations, but neither field can effectively investigate this pathway alone. Moving forward, interdisciplinary research teams are needed to build clearer definitions and better measurement tools for fractions knowledge, algebra knowledge, and mechanisms that might link them. By uniting 
the strengths and expertise of both disciplines, we can develop more precise models of the fractions-algebra pathway to inform developmental theory and move two largely disparate disciplines toward actionable models of students' learning that can inform educational practice.

(Word Count: 15,789 words) 
Adelman, C. (2006). The toolbox revisited: Paths to degree completion from high school through college. Washington, DC. https://doi.org/ED490195

Atkinson, R. C., \& Shiffrin, R. M. (1968). Human memory: A proposed system and its control processes. Psychology of Learning and Motivation, 2(4), 90-119. https://doi.org/10.1016/S0079-7421(08)60422-3

Bailey, D. H., Hoard, M. K., Nugent, L., \& Geary, D. C. (2012). Competence with fractions predicts gains in mathematics achievement. Journal of Experimental Child Psychology, 113(3), 447-455. https://doi.org/10.1016/j.jecp.2012.06.004

Bailey, D. H., Siegler, R. S., \& Geary, D. C. (2014). Early predictors of middle school fraction knowledge. Developmental Science, 17(5), 775-785. https://doi.org/10.1111/desc. 12155

Bailey, D. H., Hansen, N., \& Jordan, N. C. (2017). The codevelopment of children's fraction arithmetic skill and fraction magnitude understanding. Journal of Educational Psychology, 109(4), 509-519. https://doi.org/10.1037/edu0000152

Barbieri, C. A., Rodrigues, J., Dyson, N., \& Jordan, N. C. (2019). Improving fraction understanding in sixth graders with mathematics difficulties: Effects of a number line approach combined with cognitive learning strategies. Journal of Educational Psychology, (June). https://doi.org/10.1037/edu0000384

Barth, H. C., \& Paladino, A. M. (2011). The development of numerical estimation: Evidence against a representational shift. Developmental Science, 14(1), 125-135. https://doi.org/10.1111/j.1467-7687.2010.00962.x

Behr, M. J., Lesh, R., Post, T. R., \& Silver, E. A. (1983). Rational-number concepts. In R. Lesh \& M. Landau (Eds.), Acquisition of Mathematics Concepts and Processes (pp. 91-125). New York: Academic Press.

Blanton, M. L., \& Kaput, J. J. (2011). Functional thinking as a route into algebra in the elementary grades. ZDM-International Reviews on Mathematical Education 37,523. https://doi.org/10.1007/978-3-642-17735-4_2

Blanton, M., Brizuela, B. M., Stephens, A., Knuth, E., Isler, I., Gardiner, A. M., ... Stylianou, D. (2018). Implementing a Framework for Early Algebra, 27-49. https://doi.org/10.1007/978-3-319-68351-5_2

Blanton, M., Stephens, A., Knuth, E., Gardiner, A. M., Isler, I., \& Kim, J. S. (2015). The development of children's algebrai thinking: The impact of a comprehensive early algebra intervention in third grade. Journal for Research in Mathematics Education, 46(1), 39-87. https://doi.org/10.5951/jresematheduc.46.1.0039

Blanton, M., Stroud, R., Stephens, A., Gardiner, A. M., Stylianou, D. A., Knuth, E., ... Strachota, S. (2019). Does Early Algebra Matter? The Effectiveness of an Early 
Algebra Intervention in Grades 3 to 5. American Educational Research Journal, 56(5), 1930-1972. https://doi.org/10.3102/0002831219832301

Boaler, J., \& Greeno, J. G. (2000). Identity, agency, and knowing in mathematics worlds. In J. Boaler (Ed.), Multiple perspectives on mathematics teachinga and learning (Vol. 1, pp. 171-200). Boston: Greenwood Publishing Group.

Booth, J. L., \& Newton, K. J. (2012). Fractions: Could they really be the gatekeeper's doorman? Contemporary Educational Psychology, 37(4), 247-253. https://doi.org/10.1016/j.cedpsych.2012.07.001

Booth, J. L., Newton, K. J., \& Twiss-Garrity, L. K. (2014a). The impact of fraction magnitude knowledge on algebra performance and learning. Journal of Experimental Child Psychology, 118(1), 110-118. https://doi.org/10.1016/j.jecp.2013.09.001

Booth, J. L., Barbieri, C., Eyer, F., \& Paré-Blagoev, E. J. (2014b). Persistent and pernicious errors in algebraic problem solving. Journal of Problem Solving, 7(1), 10-23. https://doi.org/10.7771/1932-6246.1161

Booth, J. L., \& Siegler, R. S. (2006). Developmental and individual differences in pure numerical estimation. Developmental Psychology, 42(1), 189-201. https://doi.org/10.1037/0012-1649.41.6.189

Braithwaite, D. W., Goldstone, R. L., van der Maas, H. L. J., \& Landy, D. H. (2016). Informal mechanisms in mathematical cognitive development: The case of arithmetic. Cognition, 149, 40-55. https://doi.org/10.1016/j.cognition.2016.01.004

Brizuela, B. M., \& Earnest, D. (2017). Multiple notational systems and algebraic understandings: The case of the "best deal" problem. In J. J. Kaput, D. W. Carraher, \& M. L. Blanton (Eds.), Algebra In The Early Grades (pp. 273-302). New York: Lawrence Erlbaum Associates.

Brown, G., \& Quinn, R. J. (2007). Fraction proficiency and succes in Algebra. AMT, 63(3), 23-31.

Bruner, J. (1960). The process of education. New York: Vintage Books.

Burris, C. C., Heubert, J. P., \& Levin, H. M. (2004). Math acceleration for all. Educational Leadership, 61(5), 68-71.

Byerley, C. (2019). Calculus students' fraction and measure schemes and implications for teaching rate of change functions conceptually. Journal of Mathematical Behavior. https://doi.org/10.1016/j.jmathb.2019.03.001

Byrd, C. E., McNeil, N. M., Chesney, D. L., \& Matthews, P. G. (2015). A specific misconception of the equal sign acts as a barrier to children's learning of early algebra. Learning and Individual Differences, 38, 61-67. https://doi.org/10.1016/j.lindif.2015.01.001 
Cai, J., \& Knuth, E. J. (Eds.). (2011). Early Algebraization: A Global Dialogue from Multiple Perspectives. New York: Springer.

Carpenter, T. P., Franke, M. L., \& Levi, L. (2003). Thinking Mathematically: Integrating Arithmetic and Algebra in Elementary School. Portsmouth, NH: Heinemann.

Carraher, D. W., Martinez, M. V., \& Schliemann, A. D. (2008). Early algebra and mathematical generalization. ZDM - International Journal on Mathematics Education, 40(1), 3-22. https://doi.org/10.1007/s11858-007-0067-7

Charalambous, C. Y., \& Pitta-Pantazi, D. (2007). Drawing on a theoretical model to study students' understandings of fractions. Educational Studies in Mathematics, 64(3), 293-316. https://doi.org/10.1007/s10649-006-9036-2

Chen, X. (2014). STEM attrition: College students' paths into and out of STEM fields. Statistical Analysis Report (NCES2014-001). Washington, DC.

Chesney, D. L., \& Matthews, P. G. (2013). Knowledge on the line: Manipulating beliefs about the magnitudes of symbolic numbers affects the linearity of line estimation tasks. Psychonomic Bulletin \& Review, 20(6), 1146-1153. https://doi.org/10.3758/s13423-013-0446-8

Christou, K. P., \& Vosniadou, S. (2012). What Kinds of Numbers Do Students Assign to Literal Symbols? Aspects of the Transition from Arithmetic to Algebra. Mathematical Thinking and Learning, 14(1), 1-27. https://doi.org/10.1080/10986065.2012.625074

Cleary, T. J., \& Chen, P. P. (2009). Self-regulation, motivation, and math achievement in middle school: Variations across grade level and math context. Journal of School Psychology, 47(5), 291-314. https://doi.org/10.1016/j.jsp.2009.04.002

Clements, D. H., \& Sarama, J. S. (2014). Learning trajectories: Foundations for effective, research-based education. In A. P. Maloney, J. Confrey, \& K. H. Nguyen (Eds.), Learning Over Time: Learning Trajectories in Mathematics Education (pp. 1-30). Charlotte, N.C.: Information Age Publishing.

Cohen, D. J., \& Quinlan, P. T. (2018). The log-linear response function of the bounded number-line task is unrelated to the psychological representation of quantity. Psychonomic Bulletin and Review, 25(1), 447-454. https://doi.org/10.3758/s13423-017-1290-z

Confrey, J., Maloney, A. P., \& Corley, A. K. (2014). Learning trajectories: a framework for connecting standards with curriculum. ZDM - International Journal on Mathematics Education, 46(5), 719-733. https://doi.org/10.1007/s11858-0140598-7

Dauber, S. L., Alexander, K. L., \& Entwisle, D. R. (1996). Tracking and transitions through the middle grades: Channeling educational trajectories. Sociology of Education, 69(4), 290-307. 
DeWolf, M., Bassok, M., \& Holyoak, K. J. (2016). A set for relational reasoning: Facilitation of algebraic modeling by a fraction task. Journal of Experimental Child Psychology, 152, 351-366. https://doi.org/10.1016/j.jecp.2016.06.016

DeWolf, M., Bassok, M., \& Holyoak, K. J. (2015a). From rational numbers to algebra: Separable contributions of decimal magnitude and relational understanding of fractions. Journal of Experimental Child Psychology, 133, 72-84. https://doi.org/10.1016/j.jecp.2015.01.013

DeWolf, M., Bassok, M., \& Holyoak, K. J. (2015b). Conceptual structure and the procedural affordances of rational numbers: Relational reasoning with fractions and decimals. Journal of Experimental Psychology: General, 144(1), 127-150. https://doi.org/10.1037/xge0000034

DeWolf, M., Grounds, M. A., Bassok, M., \& Holyoak, K. J. (2014). Magnitude comparison with different types of rational numbers. Journal of Experimental Psychology: Human Perception and Performance, 40(1), 71-82. https://doi.org/10.1037/a0032916

Dewolf, M., \& Holyoak, K. J. (2014). Reciprocal and Multiplicative Relational Reasoning with Rational Numbers. In Proceedings of the Annual Meeting of the Cognitive Science Society (Vol. 36, pp. 2139-2144). Retrieved from https://cloudfront.escholarship.org/dist/prd/content/qt8mw1q07z/qt8mw1q07z.pdf

Driscoll, M. (1999). Fostering Algebraic Thinking: A Guide for Teachers, Grades 6-10. Portsmouth, NH: Heinemann.

Dweck, C. S. (2006). Mindset: The new psychology of success. New York: Random House.

Ellis, A. B. (2007). Connections between generalizing and justifying: Students' reasoning with linear relationships. Journal for Research in Mathematics Education, 38(3), 194-229.

Empson, S. B., Levi, L., \& Carpenter, T. P. (2011). The algebraic nature of fractions: Developing relational thinking in elementary school. In J. Cai \& E. J. Knuth (Eds.), Early Algebraization: A Global Dialogue from Multiple Perspectives (pp. 408428). New York: Springer.

Fazio, L. K., Kennedy, C. A., \& Siegler, R. S. (2016). Improving children's knowledge of fraction magnitudes. PLoS ONE, 11(10). https://doi.org/10.1371/journal.pone.0165243

Froiland, J. M., \& Davison, M. L. (2016). The longitudinal influences of peers, parents, motivation, and mathematics course-taking on high school math achievement. Learning and Individual Differences, 50, 252-259. https://doi.org/10.1016/j.lindif.2016.07.012 
Froiland, J. M., \& Worrell, F. C. (2016). Intrinsic motivation, learning goals, engagement, and achievement in a diverse high school. Psychology in the Schools, 53(3), 321-336. https://doi.org/10.1002/pits

Fuchs, L. S., Malone, A. S., Schumacher, R. F., Namkung, J., Hamlett, C. L., Jordan, N. C., ... Changas, P. (2016). Supported self-explaining during fraction intervention. Journal of Educational Psychology, 108(4), 493-508. https://doi.org/10.1037/edu0000073

Fuchs, L. S., Schumacher, R. F., Sterba, S. K., Long, J., Namkung, J., Malone, A., ... Changas, P. (2014). Does working memory moderate the effects of fraction intervention? An aptitude-treatment interaction. Journal of Educational Psychology, 106(2), 499-514. https://doi.org/10.1037/a0034341

Fuchs, L. S., Malone, A. S., Schumacher, R. F., Namkung, J., \& Wang, A. (2017). Fraction intervention for students with mathematics difficulties: Lessons learned from five randomized controlled trials. Journal of Learning Disabilities, 50(6), 631-639. https://doi.org/10.1177/0022219416677249

Fuchs, L. S., Schumacher, R. F., Long, J., Namkung, J., Hamlett, C. L., Cirino, P. T., ... Changas, P. (2013). Improving at-risk learners' understanding of fractions. Journal of Educational Psychology, 105(3), 683-700. https://doi.org/10.1037/a0032446

Fyfe, E. R., Matthews, P. G., Amsel, E., McEldoon, K. L., \& McNeil, N. M. (2018). Assessing formal knowledge of math equivalence among algebra and pre-algebra students. Journal of Educational Psychology, 110(1), 87-101. https://doi.org/10.1037/edu0000208

Gamoran, A., \& Hannigan, E. C. (2000). Algebra for everyone? Benefits of collegepreparatory mathematics for students with diverse abilities in early secondary school. Educational Evaluation and Policy Analysis Fall, 22(3), 241-254. https://doi.org/10.3102/01623737022003241

Gamoran, A., \& Mare, R. D. (1989). Secondary school tracking and educational inequality: Compensation, reinforcement, or neutrality. American Journal of Sociology, 94(5), 1146-1183.

Goldenberg, E. P., Mark, J., \& Cuoco, A. (2010). An Algebraic-Habits-of-Mind Perspective on Elementary School. Teaching Children Mathematics, 16(9), 9. Retrieved from http://eric.ed.gov/ERICWebPortal/recordDetail?accno=EJ888300

Goldenberg, E. P., Mark, J., Kang, J. M., Fries, M., Carter, C. J., \& Cordner, T. (2015). Making sense of algebra: Developing students' mathematical habits of mind. Portsmouth, NH: Heinemann.

Goldstone, R. L., Marghetis, T., Weitnauer, E., Ottmar, E. R., \& Landy, D. (2017). Adapting Perception, Action, and Technology for Mathematical Reasoning. Current Directions in Psychological Science, 26(5), 434-441. https://doi.org/10.1177/0963721417704888 
Gottfried, A. E., Marcoulides, G. A., Gottfried, A. W., \& Oliver, P. H. (2013).

Longitudinal Pathways From Math Intrinsic Motivation and Achievement to Math Course Accomplishments and Educational Attainment. Journal of Research on Educational Effectiveness, 6(1), 68-92.

https://doi.org/10.1080/19345747.2012.698376

Gray, E. M., \& Tall, D. O. (1994). Duality, Ambiguity, and Flexibility: A "Proceptual" View of Simple Arithmetic. Journal for Research in Mathematics Education, 25(2), 116-140. https://doi.org/10.5951/jresematheduc.25.2.0116

Hackenberg, A. J. (2007). Units coordination and the construction of improper fractions: A revision of the splitting hypothesis. Journal of Mathematical Behavior, 26(1), 27-47. https://doi.org/10.1016/j.jmathb.2007.03.002

Hackenberg, A. J. (2010). Students' reasoning with reversible multiplicative relationships. Cognition and Instruction, 28(4), 383-432. https://doi.org/10.1080/07370008.2010.511565

Hackenberg, A. J. (2013). The fractional knowledge and algebraic reasoning of students with the first multiplicative concept. Journal of Mathematical Behavior, 32(3), 538-563. https://doi.org/10.1016/j.jmathb.2013.06.007

Hackenberg, A. J., Jones, R., Eker, A., \& Creager, M. (2017). “Approximate” multiplicative relationships between quantitative unknowns. Journal of Mathematical Behavior, 48, 38-61. https://doi.org/10.1016/j.jmathb.2017.07.002

Hackenberg, A. J., \& Lee, M. Y. (2011). Pre-fractional middle school students' algebraic reasoning. In Proceedings of the 34th annual meeting of the North American Chapter of the International Group for the Psychology of Mathematics Education (pp. 943-950). Kalamazoo, MI: Western Michigan University.

Hackenberg, A. J., \& Lee, M. Y. (2015). Relationships between students' fractional knowledge and equation writing. Journal for Research in Mathematics Education, 46(2), 196-243.

Hackenberg, A. J., \& Lee, M. Y. (2016). Students' distributive reasoning with fractions and unknowns. Educational Studies in Mathematics, 93(2), 245-263. https://doi.org/10.1007/s10649-016-9704-9

Hackenberg, A. J., \& Tillema, E. S. (2009). Students' whole number multiplicative concepts: A critical constructive resource for fraction composition schemes. Journal of Mathematical Behavior, 28(1), 1-18. https://doi.org/10.1016/j.jmathb.2009.04.004

Hamdan, N., \& Gunderson, E. A. (2017). The number line is a critical spatial-numerical representation: Evidence from a fraction intervention. Developmental Psychology, 53(3), 587-596. https://doi.org/10.1037/dev0000252

Hansen, N., Jordan, N. C., Fernandez, E., Siegler, R. S., Fuchs, L., Gersten, R., \& Micklos, D. (2015). General and math-specific predictors of sixth-graders' 
knowledge of fractions. Cognitive Development, 35, 34-49.

https://doi.org/10.1016/j.cogdev.2015.02.001

Hansen, N., Jordan, N. C., \& Rodrigues, J. (2017a). Identifying learning difficulties with fractions: A longitudinal study of student growth from third through sixth grade. Contemporary Educational Psychology, 50, 45-59.

https://doi.org/10.1016/j.cedpsych.2015.11.002

Hansen, N., Rinne, L., Jordan, N. C., Ye, A., Resnick, I., \& Rodrigues, J. (2017b). Codevelopment of fraction magnitude knowledge and mathematics achievement from fourth through sixth grade. Learning and Individual Differences, 60, 18-32. https://doi.org/10.1016/j.lindif.2017.10.005

Harden, R. M., \& Stamper, N. (1999). What is a spiral curriculum? Medical Teacher, 21(2), 141-143. https://doi.org/10.1080/01421599979752

Hecht, S. A., \& Vagi, K. J. (2012). Patterns of strengths and weaknesses in children's knowledge about fractions. Journal of Experimental Child Psychology, 111(2), 212-229. https://doi.org/10.1016/j.jecp.2011.08.012

Hurst, M. A., \& Cordes, S. (2018a). Children's understanding of fraction and decimal symbols and the notation-specific relation to pre-algebra ability. Journal of Experimental Child Psychology, 168, 32-48. https://doi.org/10.1016/j.jecp.2017.12.003

Hurst, M., \& Cordes, S. (2018b). A systematic investigation of the link between rational number processing and algebra ability. British Journal of Psychology, 109(1), 99117. https://doi.org/10.1111/bjop.12244

Hurst, M., Leigh Monahan, K., Heller, E., \& Cordes, S. (2014). 123s and ABCs: Developmental shifts in logarithmic-to-linear responding reflect fluency with sequence values. Developmental Science, 17(6), 892-904. https://doi.org/10.1111/desc.12165

Jang, H., Kim, E. J., \& Reeve, J. (2012). Longitudinal test of self-determination theory's motivation mediation model in a naturally occurring classroom context. Journal of Educational Psychology, 104(4), 1175-1188. https://doi.org/10.1037/a0028089

Jiang, M. J., Cooper, J. L., \& Alibali, M. W. (2014). Spatial factors influence arithmetic performance: The case of the minus sign. Quarterly Journal of Experimental Psychology, 67(8), 1626-1642. https://doi.org/10.1080/17470218.2014.898669

Jones, I., Inglis, M., Gilmore, C., \& Dowens, M. (2012). Substitution and sameness: Two components of a relational conception of the equals sign. Journal of Experimental Child Psychology, 113(1), 166-176. https://doi.org/10.1016/j.jecp.2012.05.003

Kail, R., \& Bisanz, J. (1992). The information-processing perspective on cognitive development in childhood and adolescence. Intellectual Development, (1976), 249-265. 
Kaput, J. J. (1998). Transforming algebra from an engine of inequity to an engine of mathematical power by "algebrafying" the K-12 curriculum. In S. Fennel (Ed.), The nature and role of algebra in the K-14 curriculum: Proceedings of a National Symposium (pp. 25-26). National Research Council, National Academies Press.

Kaput, J. J. (2008). What is algebra? What is algebraic reasoning? In J. J. Kaput, D. W. Carraher, \& M. L. Blanton (Eds.), Algebra In The Early Grades (pp. 5-17). New York: Lawrence Erlbaum Associates.

Kaput, J. J., \& West, M. M. (1994). Missing-value proportional reasoning problems: Factors affecting informal reasoning in patterns. In The development of multiplicative reasoning in the learning of mathematics.

Kieran, C. (2007). Learning and teaching algebra at the middle school through college levels. Building meaning for symbols and their manipulation. Second Handbook of Research on Mathematics Teaching and Learning, 707-762.

Kieran, C., Pang, J., Schifter, D., \& Ng, S. F. (2016). Early algebra: Research into its nature, its learning, its teaching. ICME-13 Topical Surveys. Hamburg: SpringerOpen.

Kieren, T. E. (1976). On the mathematical, cognitive, and instructional foundations of rational numbers. In R. A. Lesh \& D. A. Bradbard (Eds.), Number and Measurement: Papers from a Research Workshop. (pp. 101-140). Athens, GA: Georgia Center for the Study of Learning and Teaching Mathematics.

Kieren, T. E. (1980). The rational number construct: Its elements and mechanisms. In Recent Research on Number Learning (pp. 125-150).

Knuth, E. J., Alibali, M. W., McNeil, N. M., Weinberg, A., \& Stephens, A. C. (2005). Middle School Students' Understanding of Core Algebraic Concepts: Equivalence \& Variable. ZDM - International Journal on Mathematics Education, 37(1), 6876. https://doi.org/10.1007/bf02655899

Knuth, E. J., Stephens, A. C., McNeil, N. M., \& Alibali, M. W. (2006). Does understanding the equal sign matter? Evidence from solving equations. Journal for Research in Mathematics Education, 37(4), 297-312.

Koedinger, K. R., Alibali, M. W., \& Nathan, M. J. (2008). Trade-offs between grounded and abstract representations: Evidence from algebra problem solving. Cognitive Science, 32(2), 366-397. https://doi.org/10.1080/03640210701863933

Kriegbaum, K., Jansen, M., \& Spinath, B. (2014). Motivation: A predictor of PISA's mathematical competence beyond intelligence and prior test achievement. Learning and Individual Differences, 43, 140-148. https://doi.org/10.1016/j.lindif.2015.08.026

Landy, D. H., \& Goldstone, R. L. (2009). How much of symbolic manipulation is just symbol pushing? Proceedings of the 31st Annual Conference of the Cognitive 
Science Society, 1318-1323. Retrieved from

http://csjarchive.cogsci.rpi.edu/Proceedings/2009/papers/253/paper253.pdf

Landy, D., Allen, C., \& Zednik, C. (2014). A perceptual account of symbolic reasoning. Frontiers in Psychology, 5(APR), 1-10. https://doi.org/10.3389/fpsyg.2014.00275

Laski, E. V, \& Siegler, R. S. (2007). Is 27 a big number? Correlational and causal connections among numerical categorization, number line estimation, and numerical magnitude comparison. Child Development, 78(6), 1723-1743. Retrieved from http://www.jstor.org/stable/4620734

Liang, J. H., Heckman, P. E., \& Abedi, J. (2018). Prior Year's Predictors of EighthGrade Algebra Achievement. Journal of Advanced Academics, 29(3), 249-269. https://doi.org/10.1177/1932202X18770172

Luwel, K., Peeters, D., \& Verschaffel, L. (2019). Developmental Change in Number Line Estimation: A Strategy-Based Perspective. Canadian Journal of Experimental Psychology. https://doi.org/10.1037/cep0000172

MacDonald, B. L., \& Wilkins, J. L. M. (2019). Subitising activity relative to units construction: a case study. Research in Mathematics Education, 21(1), 77-95. https://doi.org/10.1080/14794802.2019.1579667

MacGregor, M., \& Stacey, K. (1993). Cognitive models underlying students ' formulation of simple linear equations. Journal for Research in Mathematics Education, 24(3), 217-232.

Marghetis, T., Landy, D., \& Goldstone, R. L. (2016). Mastering algebra retrains the visual system to perceive hierarchical structure in equations. Cognitive Research: Principles and Implications, 1(25), 1-10. https://doi.org/10.1186/s41235-0160020-9

Matthews, P. G., \& Ellis, A. B. (2018). Natural alternatives to natural number: The case of ratio. Journal of Numerical Cognition, 4(1), 19-58.

https://doi.org/10.5964/jnc.v4i1.97

Matthews, P. G., \& Fuchs, L. S. (2020). Keys to the gate? Equal sign knowledge at second grade predicts fourth-grade algebra competence. Child Development, 91(1), e14-e28. https://doi.org/10.1111/cdev.13144

Matthews, P. G., Rittle-Johnson, B., McEldoon, K., \& Taylor, R. (2012). Measure for measure: What combining diverse measures reveals about children's understanding of the equal sign as an indicator of mathematical equality. Journal for Research in Mathematics Education, 43(3), 316. https://doi.org/10.5951/jresematheduc.43.3.0316

Mcneil, N. M. (2014). A change-resistance account of children's difficulties understanding mathematical equivalence. Child Development Perspectives, 8(1), 42-47. https://doi.org/10.1111/cdep. 12062 
McNeil, N. M., \& Alibali, M. W. (2004). You'll see what you mean: Students encode equations based on their knowledge of arithmetic. Cognitive Science, 28(3), 451466. https://doi.org/10.1016/j.cogsci.2003.11.002

Moses, R. P., \& Cobb, C. E. (2001). Radical Equations: Math Literacy and Civil Rights. Boston: Beacon Press.

Moss, J., \& Case, R. (1999). Developing children's understanding of the rational Numbers: A new model and an experimental curriculum. Journal for Research in Mathematics Education, 30(2), 122-147. Retrieved from http://www.jstor.org/stable/749607

Nabors, W. K. (2003). From fractions to proportional reasoning: A cognitive schemes of operation approach. Journal of Mathematical Behavior, 22(2), 133-179. https://doi.org/10.1016/S0732-3123(03)00018-X

Nathan, M. J., \& Koellner, K. (2007). A framework for understanding and cultivating the transition from arithmetic to algebraic reasoning. Mathematical Thinking and Learning, 9(3), 179-192. https://doi.org/10.1080/10986060701360852

Nathan, M. J., Long, S. D., \& Alibali, M. W. (2002). The symbol precedence view of mathematical development: A corpus analysis of the rhetorical structure of textbooks. Discourse Processes, 33(1), 1-21. https://doi.org/10.1207/s15326950dp3301_01

National Center for Education Statistics (NCES). (2019). National Assessment of Educational Progress Report Card: 2019 NAEP Mathematics Assessment. Washington, DC.

National Council of Teachers of Mathematics (NCTM). (2000). Principles and Standards for School Mathematics. Reston, VA.

National Governors Association (NGA). (2010). Common Core State Standards for Mathematics. Washington, DC.

National Mathematics Advisory Panel (NMAP). (2008). Foundations for Success: The Final Report of the National Mathematics Advisory Panel. Washington, DC. https://doi.org/10.3102/0013189X08329195

Ni, Y., \& Zhou, Y.-D. (2005). Teaching and learning fraction and rational numbers: The origins and implications of whole number bias. Educational Psychologist, 40(1), 27-52. https://doi.org/10.1207/s15326985ep4001_3

Norton, A., Boyce, S., Phillips, N., Anwyll, T., Ulrich, C., \& Wilkins, J. L. M. (2015). A written instrument for assessing students' units coordination structures. International Electronic Journal of Mathematics Education, 10(2), 111-136. https://doi.org/10.12973/mathedu.2015.108a 
Norton, A., \& Hackenberg, A. J. (2010). Continuing research on students' fraction schemes. In L. P. Steffe \& J. Olive (Eds.), Children's Fractional Knowledge (pp. 341-352). New York: Springer. https://doi.org/10.1007/978-1-4419-0591-8

Norton, A., \& Wilkins, J. L. M. (2009). A quantitative analysis of children's splitting operations and fraction schemes. Journal of Mathematical Behavior, 28(2-3), 150161. https://doi.org/10.1016/j.jmathb.2009.06.002

Norton, A., \& Wilkins, J. L. M. (2010). Students' partitive reasoning. Journal of Mathematical Behavior, 29(4), 181-194. https://doi.org/10.1016/j.jmathb.2010.10.001

Obersteiner, A., \& Tumpek, C. (2016). Measuring fraction comparison strategies with eye-tracking. ZDM - Mathematics Education, 48(3), 255-266. https://doi.org/10.1007/s11858-015-0742-z

Obersteiner, A., Van Dooren, W., Van Hoof, J., \& Verschaffel, L. (2013). The natural number bias and magnitude representation in fraction comparison by expert mathematicians. Learning and Instruction, 28, 64-72. https://doi.org/10.1016/j.learninstruc.2013.05.003

Ohlsson, S. (1988). Mathematical meaning and applicational meaning in the semantics of fractions and related concepts. In J. Hiebert \& M. Behr (Eds.), Number Concepts and Operations in the Middle Grades (pp. 91-125). Reston, VA: National Council of Teachers of Mathematics.

Olive, J., \& Çağlayan, G. (2008). Learners' difficulties with quantitative units in algebraic word problems and the teacher's interpretation of those difficulties. International Journal of Science and Mathematics Education, 6(2), 269-292. https://doi.org/10.1007/s10763-007-9107-6

Opfer, J. E., Thompson, C. A., \& Kim, D. (2016). Free versus anchored numerical estimation: A unified approach. Cognition, 149, 11-17. https://doi.org/10.1016/j.cognition.2015.11.015

Papadopoulos, I. (2019). Using mobile puzzles to exhibit certain algebraic habits of mind and demonstrate symbol-sense in primary school students. Journal of Mathematical Behavior, 53(June 2018), 210-227. https://doi.org/10.1016/j.jmathb.2018.07.001

Peck, F., \& Matassa, M. (2016). Reinventing fractions and division as they are used in algebra: the power of preformal productions. Educational Studies in Mathematics, 92(2), 245-278. https://doi.org/10.1007/s10649-016-9690-y

Peeters, D., Degrande, T., Ebersbach, M., Verschaffel, L., \& Luwel, K. (2016). Children's use of number line estimation strategies. European Journal of Psychology of Education, 31(2), 117-134. https://doi.org/10.1007/s10212-0150251-z 
Piaget, J., \& Duckworth, E. (1970). Genetic Epistemology. American Behavioral Scientist. https://doi.org/10.1177/000276427001300320

Pillay, H., Wilss, L., \& Boulton-Lewis, G. (1998). Sequential development of algebra knowledge: A cognitive analysis. Mathematics Education Research Journal, 10(2), 87-102. https://doi.org/10.1007/BF03217344

Powell, S. R., Gilbert, J. K., \& Fuchs, L. S. (2019). Variables influencing algebra performance: Understanding rational numbers is essential. Learning and Individual Differences, 74, 101758. https://doi.org/10.1016/j.lindif.2019.101758

Radford, L. (2000). Signs and meanings in students' emergent algebraic thinking: A semiotic analysis. Educational Studies in Mathematics, 42, 237-268. https://doi.org/10.2307/j.ctv13841gj.9

RAND Mathematics Study Panel Report. (2003). Mathematical proficiency for all students: A strategic research and development program in mathematics education. Washington, DC.

Rinne, L. F., Ye, A., \& Jordan, N. C. (2017). Development of fraction comparison strategies: A latent transition analysis. Developmental Psychology, 53(4), 713-730. https://doi.org/10.1037/dev0000275

Rittle-Johnson, B., Matthews, P. G., Taylor, R. S., \& McEldoon, K. L. (2011). Assessing knowledge of mathematical equivalence: A construct-modeling approach. Journal of Educational Psychology, 103(1), 85-104. https://doi.org/10.1037/a0021334

Rosenberg-Lee, M. (2018). Training studies: An experimental design to advance educational neuroscience. Mind, Brain, and Education, 12(1), 12-22. https://doi.org/10.1111/mbe.12166

Schneider, E., Maruyama, M., Dehaene, S., \& Sigman, M. (2012). Eye gaze reveals a fast, parallel extraction of the syntax of arithmetic formulas. Cognition, 125(3), 475-490. https://doi.org/10.1016/j.cognition.2012.06.015

Sfard, A. (1991). On the dual nature of mathematical conceptions: Reflections on processes and objects as different sides of the same coin. Educational Studies in Mathematics, 22(1), 1-36. https://doi.org/10.1007/BF00302715

Sfard, A., \& Linchevski, L. (1994). The gains and the pitfalls of reification : The case of algebra. Educational Studies in Mathematics, 26(2), 191-228.

Sidney, P. G., Thompson, C. A., Fitzsimmons, C., \& Taber, J. M. (2019). Children's and adults' math attitudes are differentiated by number type. Journal of Experimental Education, O(0), 1-32. https://doi.org/10.1080/00220973.2019.1653815 
Siegler, R. S., \& Booth, J. L. (2004). Development of numerical estimation in young children. Child Development, 75(2), 428-444. https://doi.org/10.1111/j.14678624.2004.00684.x

Siegler, R. S., \& Pyke, A. A. (2013). Developmental and individual differences in understanding of fractions. Developmental Psychology, 49(10), 1994-2004. https://doi.org/10.1037/a0031200

Siegler, R. S., Duncan, G. J., Davis-Kean, P. E., Duckworth, K., Claessens, A., Engel, M., ... Chen, M. (2012). Early predictors of high school mathematics achievement. Psychological Science, 23(7), 691-697. https://doi.org/10.1177/0956797612440101

Siegler, R. S., \& Opfer, J. E. (2003). The development of numerical estimation: Evidence for multiple representations of numerical quantity. Psychological Science, 14(3), 237-243. https://doi.org/10.1111/1467-9280.02438

Siegler, R. S., Thompson, C. A., \& Schneider, M. (2011). An integrated theory of whole number and fractions development. Cognitive Psychology, 62(4), 273-296. https://doi.org/10.1016/j.cogpsych.2011.03.001

Simsek, E., Xenidou-Dervou, I., Karadeniz, I., \& Jones, I. (2019). The conception of substitution of the equals sign plays a unique role in students' Algebra performance. Journal of Numerical Cognition, 5(1), 24-37. https://doi.org/10.5964/jnc.v5i1.147

Slusser, E. B., Santiago, R. T., \& Barth, H. C. (2013). Developmental change in numerical estimation. Journal of Experimental Psychology: General, 142(1), 193208. https://doi.org/10.1037/a0028560

Stafylidou, S., \& Vosniadou, S. (2004). The development of students' understanding of the numerical value of fractions. Learning and Instruction, 14(5 SPEC.ISS.), 503518. https://doi.org/10.1016/j.learninstruc.2004.06.015

Steffe, L. P. (1992). Schemes of action and operation involving composite units. Learning and Individual Differences, 4(3), 259-309. https://doi.org/10.1016/10416080(92)90005-Y

Steffe, L. P., \& Olive, J. (2010). Children's Fractional Knowledge. New York: Springer.

Stephens, A. C., Ellis, A. B., Blanton, M., \& Brizuela, B. M. (2017). Algebraic thinking in the elementary and middle grades. In J. Cai (Ed.), Compendium for research in mathematics education (pp. 386-420). Reston, VA: National Council of Teachers of Mathematics.

Stevens, A. L., Wilkins, J. L. M., Lovin, L. A. H., Siegfried, J., Norton, A., \& Busi, R. (2020). Promoting sophisticated fraction constructs through instructional changes in a mathematics course for PreK-8 prospective teachers. Journal of Mathematics Teacher Education, 23(2), 153-181. https://doi.org/10.1007/s10857-018-9415-5 
Stigler, J. W., Givvin, K. B., \& Thompson, B. J. (2010). What community college developmental mathematics students understand about mathematics. Mathematics Teacher, 1(3), 4-16. https://doi.org/10.1016/j.learninstruc.2014.03.002

Stigler, J. W., Gonzales, P., Kawanaka, T., Knoll, S., \& Serrano, A. (1999). The TIMSS videotape classroom study: Methods and findings from an exploratory research project on eighth-grade mathematics instruction in Germany, Japan, and the United States (NCES1999-074). Washington, DC.

Thompson, P. (1994). The development of the concept of speed and its relationship to concepts of rate. The development of multiplicative reasoning in the learning of mathematics, 179-234.

Thompson, P. W., \& Carlson, M. (2017). Variation, covariation and functions: Foundational ways of mathematical thinking. Compendium for Research in Mathematics Education, (January), 421-456.

Thompson, P. W., \& Saldanha, L. A. (2003). Fractions and multiplicative reasoning. In J. Kilpatrick, G. Martin, \& D. Schifter (Eds.), Research Companion to the Principles and Standards for School Mathematics (pp. 95-114). National Council of Teachers of Mathematics.

Torbeyns, J., Schneider, M., Xin, Z., \& Siegler, R. S. (2015). Bridging the gap: Fraction understanding is central to mathematics achievement in students from three different continents. Learning and Instruction, 37, 5-13. https://doi.org/10.1016/j.learninstruc.2014.03.002

Trusty, J., \& Niles, S. G. (2003). High-school math courses and completion of the bachelor's degree. Professional School Counseling, 7(2), 99-107. https://doi.org/Article

Tunc-Pekkan, Z. (2008). Modeling grade eight students' construction of fraction multiplying schemes and algebraic operations. The University of Georgia.

Tzur, R. (2019). Developing Fractions as multiplicative relations: A model of cognitive reorganization. In M. W. Alibali \& A. Norton (Eds.), Constructing Number: Merging Perspectives from Psychology and Math Education (pp. 163-191). Springer. https://doi.org/10.1007/978-3-030-00491-0_8

Vamvakoussi, X., Christou, K. P., \& Vosniadou, S. (2018). Bridging psychological and educational research on rational number knowledge. Journal of Numerical Cognition, 4(1), 84-106. https://doi.org/10.5964/jnc.v4i1.82

Von Glasersfeld, E. (1995). Radical Constructivism: A Way of Knowing and Learning. Studies in Mathematics Education Series: 6. https://doi.org/10.4324/9780203454220

Wigfield, A., \& Eccles, J. S. (2000). Expectancy-value theory of achievement motivation. Contemporary Educational Psychology, 25(1), 68-81. https://doi.org/10.1006/ceps.1999.1015 
Wigfield, A., \& Eccles, J. S. (2002). The development of competence beliefs, expectancies for success, and achievement values from childhood through adolescence. In A. Wigfield \& J. S. Eccles (Eds.), Development of Achievement Motivation (pp. 91-120). Academic Press. https://doi.org/10.1016/b978012750053-9/50006-1

Wilkins, J. L. M., Norton, A., \& Steven, J. (2013). Validating a written instrument for assessing students' fractions schemes and operations, 22(2), 31-54.

Wilkins, J. L. M., \& Norton, A. (2011). The splitting loope. Journal for Research in Mathematics Education, 42(4), 386-416.

Wu, H. (2001). How to prepare students for algebra. American Educator, 25(2), 10-17.

Zippert, E. L., Douglas, A. A., \& Rittle-Johnson, B. (2020). Finding patterns in objects and numbers: Repeating patterning in pre-K predicts kindergarten mathematics knowledge. Journal of Experimental Child Psychology, 200. https://doi.org/10.1016/j.jecp.2020.104965

Acknowledgements. This work was supported by the Institute of Education Sciences, U.S. Department of Education, through Award \#R305B150003 to the University of XXXXX. The opinions expressed are those of the authors and do not represent views of the U.S. Department of Education.

Declaration of interest statement. The author has no competing interests to report. 


\section{Table 1. Definitions and measurement of "fractions knowledge" in fraction-algebra}

studies

\begin{tabular}{|c|c|c|c|c|c|}
\hline $\begin{array}{c}\text { Fractions } \\
\text { Knowledge } \\
\text { Type } \\
\end{array}$ & Sources & Definition & Measurement & Example & $\begin{array}{c}\text { Correlated } \\
\text { with Algebra? }\end{array}$ \\
\hline Magnitude & $\begin{array}{l}\text { Booth \& Newton (2012); } \\
\text { Booth et al. (2014); } \\
\text { DeWolf et al. (2015a); } \\
\text { Hurst \& Cordes (2018a; } \\
\text { b); Siegler et al. (2011) }\end{array}$ & $\begin{array}{l}\text { Knowledge of fraction } \\
\text { sizes as holistic } \\
\text { numbers }\end{array}$ & $\begin{array}{l}\text { Number Line } \\
\text { Estimation; } \\
\text { Magnitude } \\
\text { Comparison }\end{array}$ & $\begin{array}{l}\text { Which fraction is } \\
\text { larger? } \\
\frac{3}{5} \quad \frac{4}{7}\end{array}$ & Yes \\
\hline Arithmetic & $\begin{array}{l}\text { Booth et al. (2014); Hurst } \\
\text { \& Cordes (2018b); Liang } \\
\text { et al. (2018); Powell et al. } \\
\text { (2019); Siegler et al. } \\
\text { (2012) }\end{array}$ & $\begin{array}{l}\text { Knowledge/fluency } \\
\text { with operations } \\
(+,-, x, \div)\end{array}$ & Fraction calculations & $4 \frac{1}{5}-2 \frac{7}{8}=$ & Yes \\
\hline Schemes & $\begin{array}{c}\text { Hackenberg (2007; 2010; } \\
\text { 2013); Hackenberg \& } \\
\text { Lee (2015); Norton \& } \\
\text { Hackenberg (2010); } \\
\text { Thompson \& Saldanha } \\
\text { (2003); Sfard \& } \\
\text { Linchevski (1994); etc. }\end{array}$ & $\begin{array}{l}\text { Use and interiorization } \\
\text { of fraction schemes - } \\
\text { goal-directed activities } \\
\text { including partitioning, } \\
\text { iterating, etc. }\end{array}$ & $\begin{array}{l}\text { Interviews, to assess } \\
\text { students' thinking } \\
\text { about carefully } \\
\text { constructed problems }\end{array}$ & $\begin{array}{l}\text { Tyrone has } \$ 21 \text {. That's } \\
1 / 7 \text { the size of } \\
\text { Cammy's amount of } \\
\text { money. Draw a picture } \\
\text { of the situation. How } \\
\text { much money does } \\
\text { Cammy have? }\end{array}$ & $\begin{array}{l}\text { Not } \\
\text { statistically } \\
\text { tested }\end{array}$ \\
\hline
\end{tabular}


Table 2. Measures of "algebra knowledge" predicted by fractions knowledge in studies from psychology.

Task

Example Sources

Example

\begin{tabular}{|c|c|c|c|}
\hline Equation solving \& simplifying & $\begin{array}{l}\text { Booth \& Newton (2012); Booth et al. } \\
\text { (2014); Hurst \& Cordes (2018a; b); } \\
\text { Powell et al. (2019) }\end{array}$ & \multicolumn{2}{|c|}{$\begin{array}{c}\text { Solve: } 4 x+5=8 \\
\text { Simplify: } 4 x-x+7 y-2 y\end{array}$} \\
\hline Feature knowledge & $\begin{array}{l}\text { Booth \& Newton (2012); Booth et al. } \\
\text { (2014); DeWolf et al (2015) }\end{array}$ & \multicolumn{2}{|c|}{ Is $4 \mathrm{x}-3$ equivalent to $3-4 \mathrm{x}$ ? } \\
\hline Equation encoding & $\begin{array}{l}\text { Booth \& Newton (2012); Booth et al. } \\
\text { (2014); Hurst \& Cordes (2018b) }\end{array}$ & \multicolumn{2}{|c|}{$\begin{array}{l}\text { Reproduce this equation after seeing it flash for } 6 \text { sec: } \\
\qquad p-5=-2 p+3\end{array}$} \\
\hline \multicolumn{4}{|c|}{ Write a number sentence to show a rule used in the table. } \\
\hline \multirow{5}{*}{ Equation writing } & \multirow{5}{*}{$\begin{array}{l}\text { DeWolf et al. (2015a); Hurst \& } \\
\quad \text { Cordes }(2018 \mathrm{a} ; 2018 \mathrm{~b})\end{array}$} & Column A & Column B \\
\hline & & 2 & 6 \\
\hline & & 3 & 7 \\
\hline & & 4 & 8 \\
\hline & & 5 & 9 \\
\hline Word problem solving & $\begin{array}{l}\text { DeWolf et al (2015a); Hurst \& } \\
\text { Cordes }(2018 b)\end{array}$ & \multicolumn{2}{|c|}{$\begin{array}{l}\text { Joe knows that a pen costs } 1 \text { zed more than a pencil. His friend } \\
\text { bought } 2 \text { pens and } 3 \text { pencils for } 17 \text { zeds. How many zeds will } \\
\text { Joe need to buy } 1 \text { pen and } 2 \text { pencils? }\end{array}$} \\
\hline
\end{tabular}

Note. Task names are taken from the source articles and do not necessarily reflect the underlying concepts measured by each task. 


\section{Table 3. Proposed mechanisms through which fractions knowledge may influence algebra knowledge.}

Proposed Mechanism 1. Deeper understanding of the number system 2. Multiplicative relational
reasoning

3. Duality of fraction symbol

\begin{abstract}
4. Interiorization of multiplicative schemes
\end{abstract}

5. Symbolic fluency

6. Motivation
Brief Explanation

Understanding of fraction magnitudes facilitates understanding of the generalized properties of number, which supports flexible interpretation of variables.

Fractions denote a ratio relation between two sets. This sets a foundation for reasoning about equality, proportionality, and other abstract algebraic relations.

Fractions denote both a process (multiplicative relation) and a structure that is the result of that process (magnitude), and algebraic reasoning requires thinking about symbols in both ways.

Students with better fractions knowledge are likely to have more advanced multiplicative schemes, including operations like disembedding and three-level units coordination, which support algebraic symbolization.

Children with fluent fraction arithmetic skills are less likely to make calculation errors in problem solving and less likely to mis-apply fraction concepts or procedures when the numerator and denominator get more complex.

Children with low fractions knowledge may experience diminished motivation to learn math, which may lead them to learn less from subsequent instruction.
Sources

Siegler et al., 2011; Christou

\& Vosniadou, 2012;

Vamvakoussi et al., 2018

DeWolf et al., 2015a; 2015b;

Kaput \& West, 1994;

Matthews \& Ellis, 2018;

Thompson, 1994; Thompson

\& Carlson, 2017

Kieren, 1976; Peck \&

Matassa, 2016; Sfard, 1991;

Sfard \& Linchevski, 1994

Hackenberg, 2007; 2010;

2013; Hackenberg \& Lee, 2011; 2015; 2016; Norton \& Hackenberg, 2010; Olive \& Caglayan 2008

Booth, Barbieri, Eyer, \& Paré-Blagoev, 2014; Brown \& Quinn, 2007; Wu, 2001

Dweck, 2006; Sidney, et al.2019; Siegler \& Pyke, 2013; Wigfield \& Eccles, 2002 
Table 4. Examples of fraction problems used by Hackenberg and Lee (2015).

Problem Question

1 This rectangle represents $3 / 5$ of a candy bar.

Draw a picture of the whole candy bar.

2 Sara's stack of CDs is $65 \mathrm{~cm}$ tall. That's 5 times the height of Roberto's stack of CDs. Can you draw a picture of this situation? How tall is Roberto's stack?

3 If you share 3 identical sub sandwiches fairly among 5 people. How much of a sandwich does each person get?

4 This rectangle is a picture of a candy bar. Draw a separate candy bar that is $9 / 7$ of that bar.

5 Tyrone has \$21. That's 1/7 the size of Cammy's amount of money. Draw a picture of this. How much money does Cammy have? How do you know? 


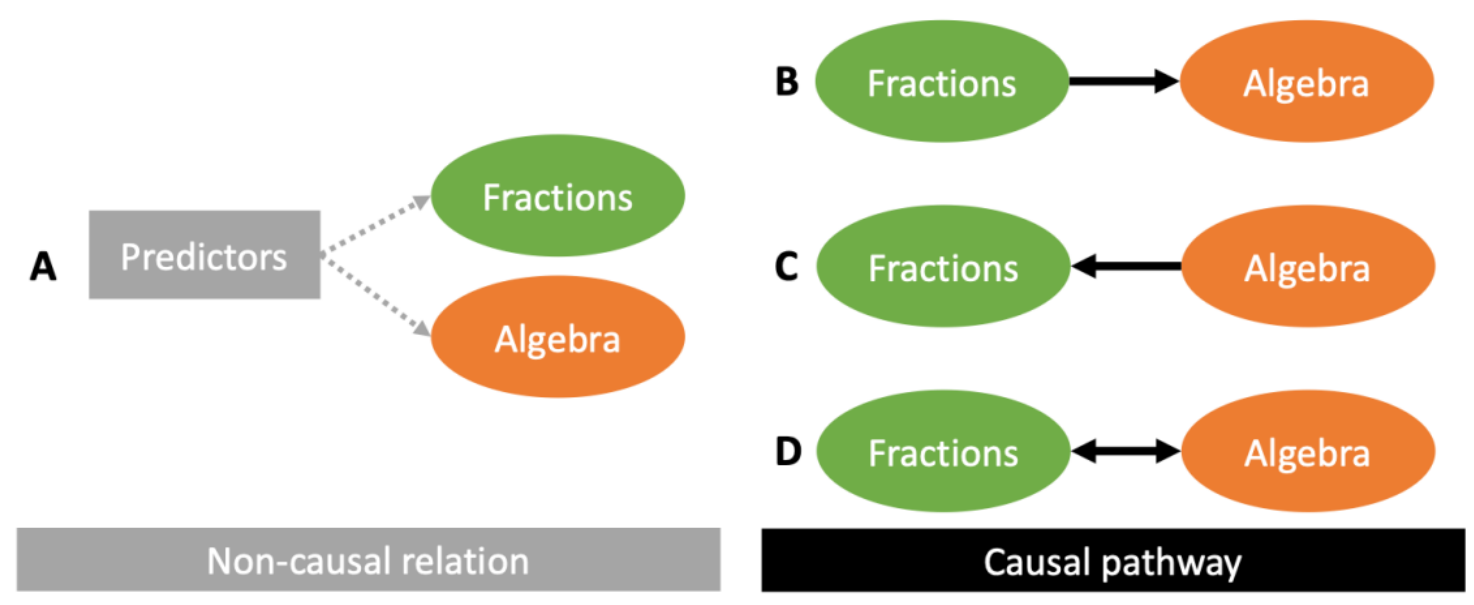

Figure 1. Fraction-algebra correlations could be explained by shared predictors (a) or a causal pathway in the predicted direction (b), opposite direction (c), or bidirectional relation (d). 


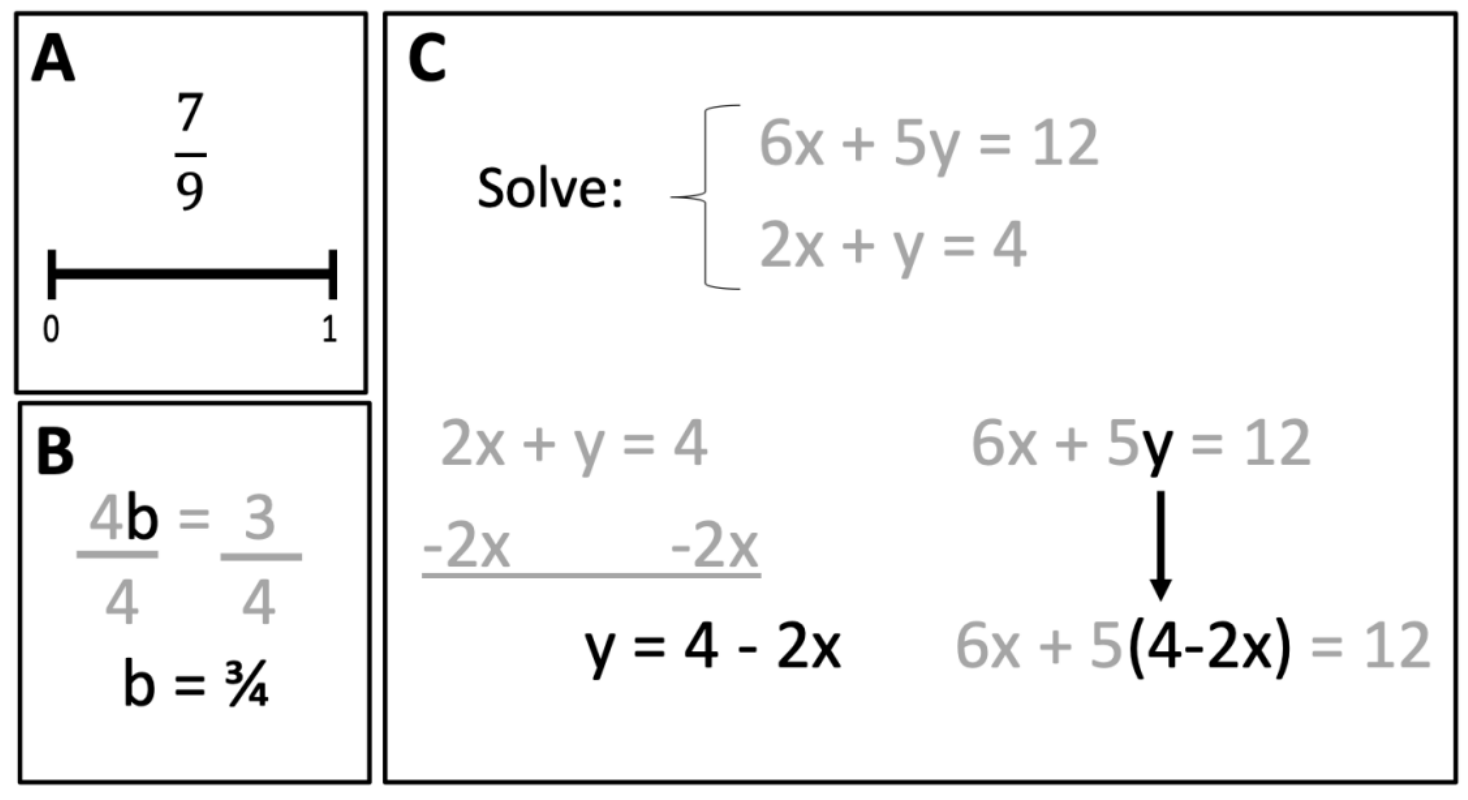

Figure 2. Students who have a better understanding of (A) a fraction as a number that can be represented on the number line with all other real numbers may have (B) a more flexible view of variables as generalized number. This deeper understanding of what a variable can represent may be helpful for more advanced algebra, such as (C) solving a system of two linear equations. 

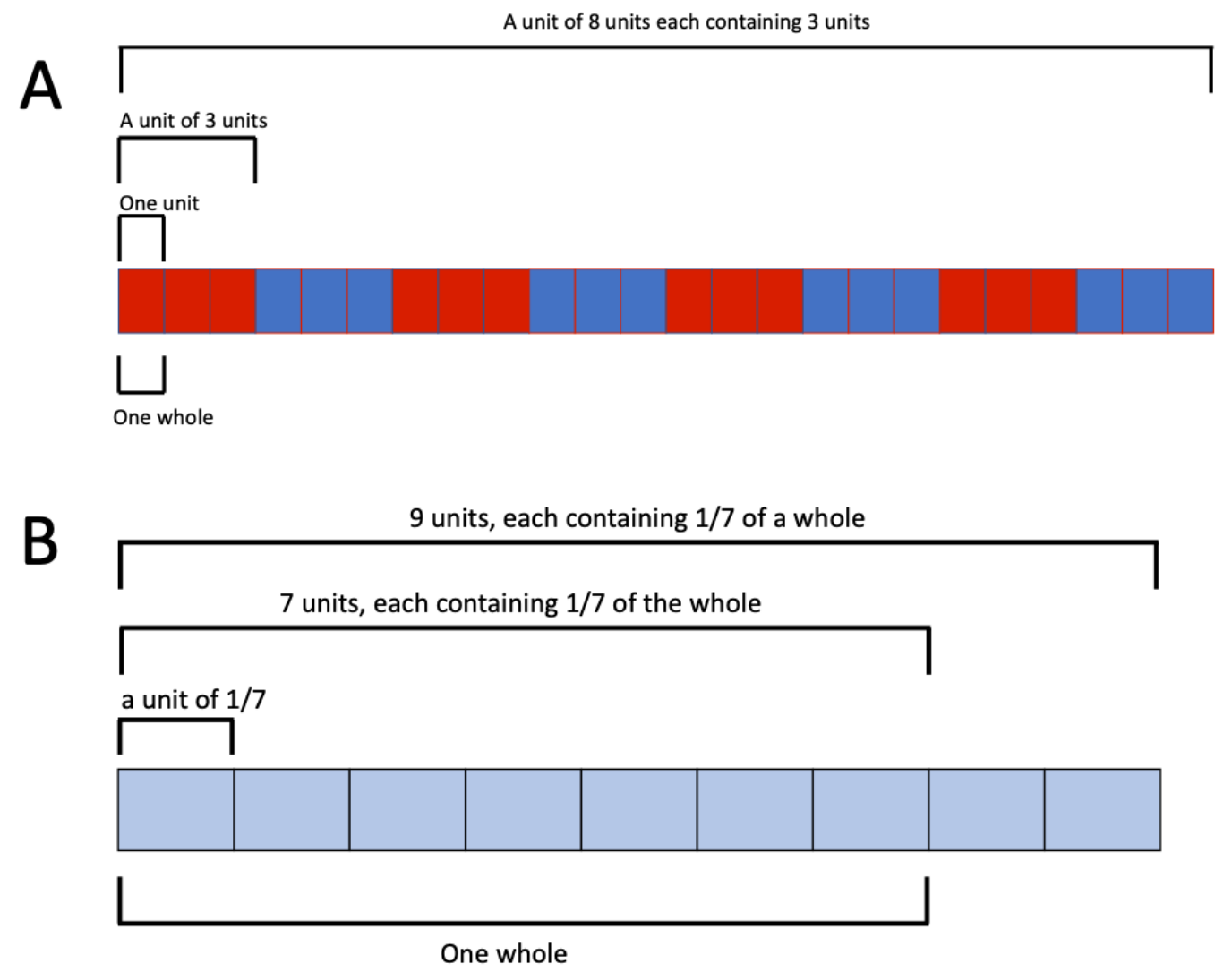

Figure 3. (A) Stimuli used in DeWolf et al. (2015a) fraction relations task (B) Example of a part-to-part ratio (PPR) and part-to-whole ratio (PWR). (C) Example PWR question from DeWolf and colleague's (2016) relational reasoning practice group. 


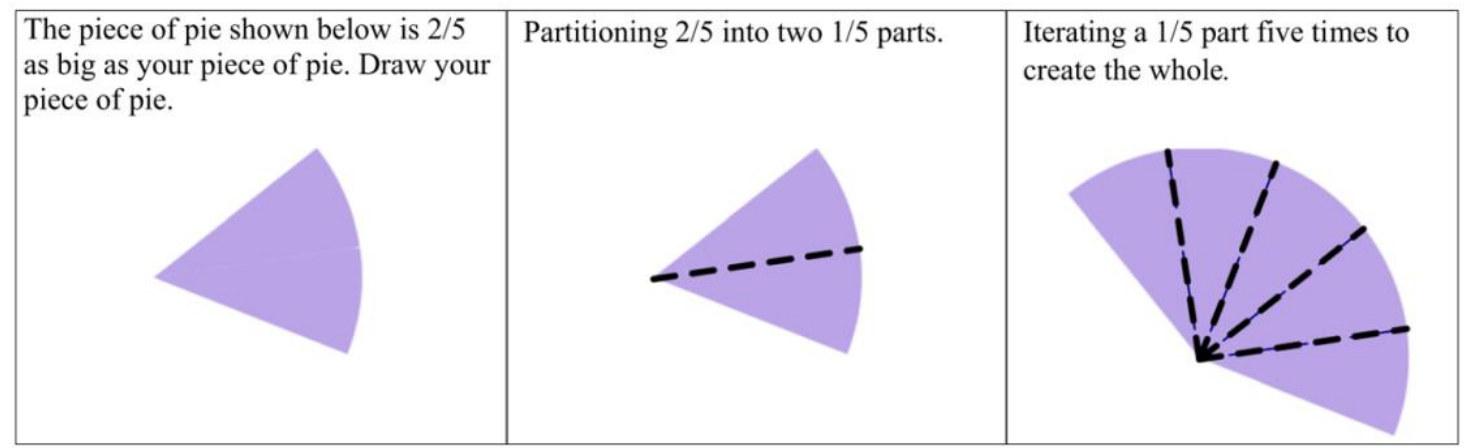

Figure 4. Illustration of three levels of units coordination with whole numbers (A) and a fraction greater than one (B). Adapted from Norton et al. (2015) with permission. 


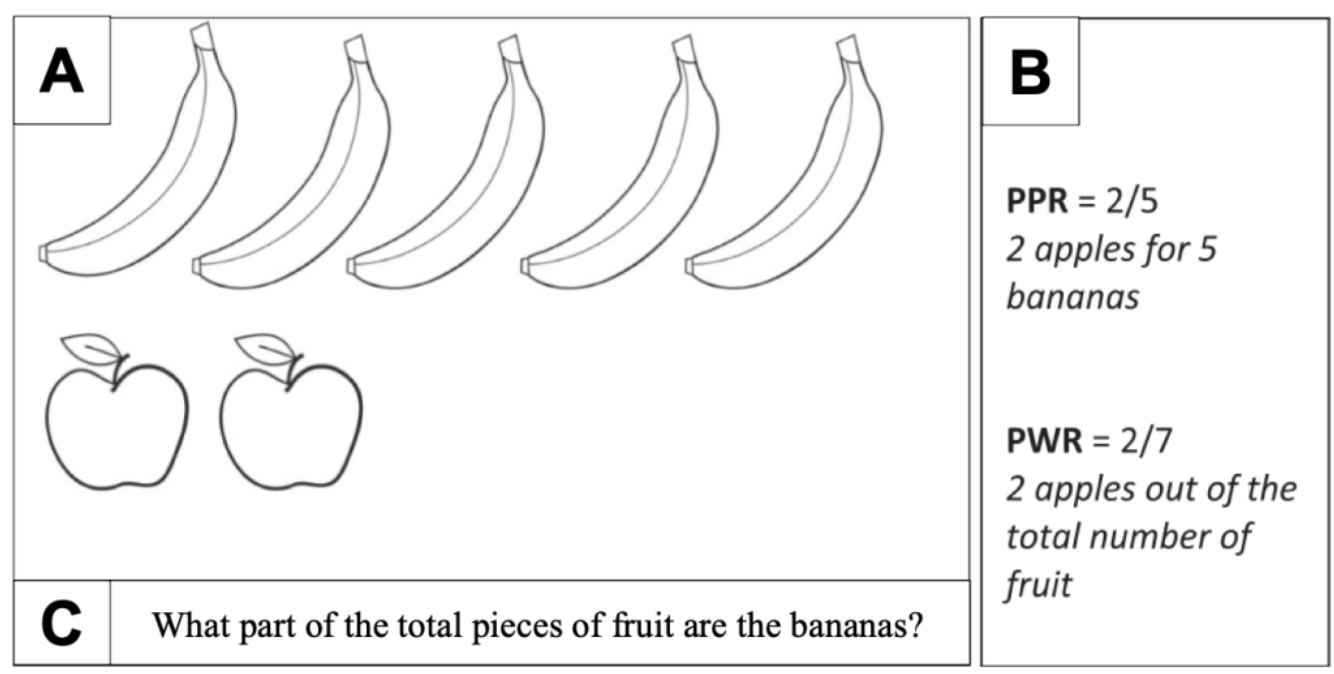

Figure 5. Example of coordinating three levels of units in activity. The original piece of pie is a unit of 2/5 which is made up of 2 units, each of which makes up 1/5 of the larger whole. This task requires children to use the relatively advanced reversible partitive fraction scheme (RPFS). Reproduced from Stevens et al. (2020) with permission. 


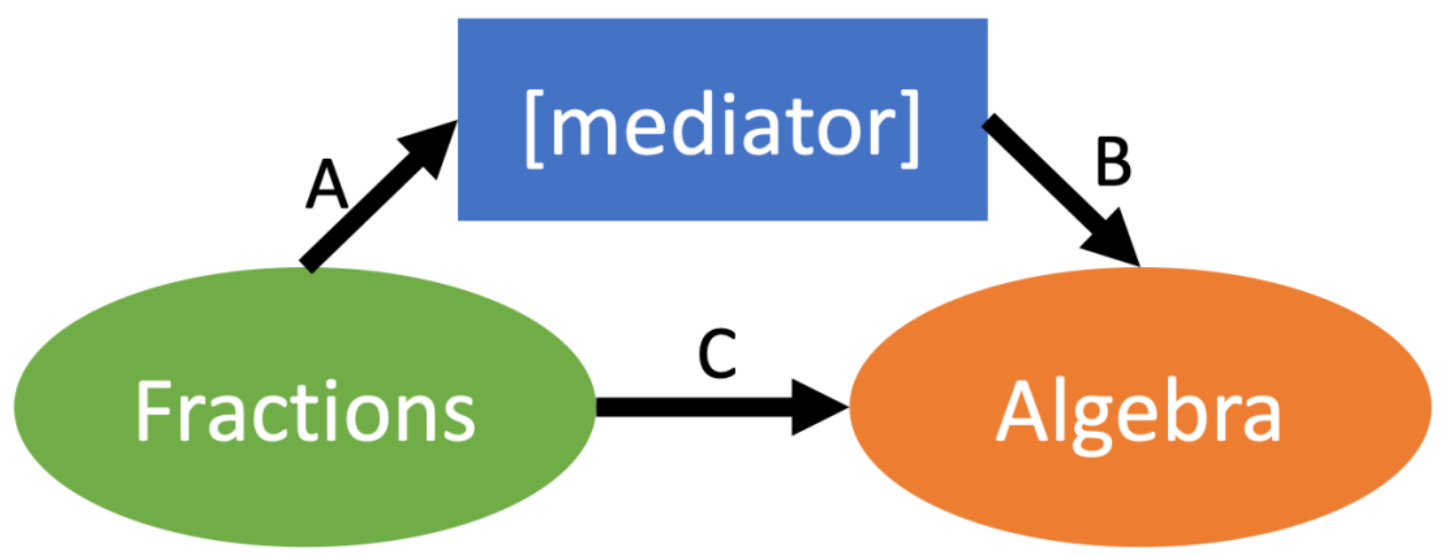

Figure 6. Diagram of a mediated causal relation between fractions and algebra knowledge. 
Student A

Inflexible, limited strategy

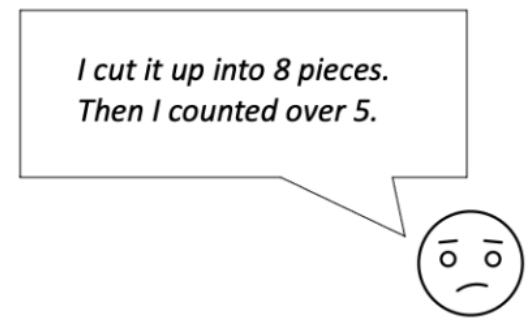

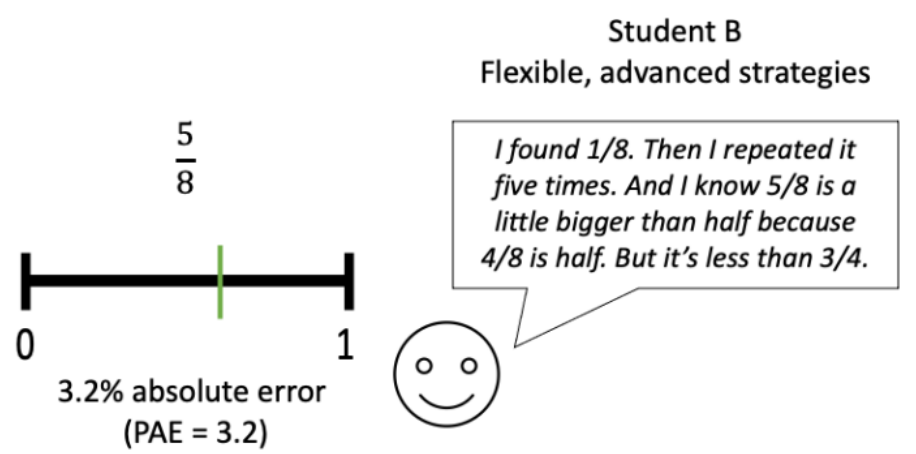

Figure 7. Illustration of two possible approaches to the popular fraction number line estimation task from psychology. Both students placed $5 / 8$ in the same position on the number line, as indicated by the green line, and so received an indistinguishable score. Without asking students their strategies, we cannot distinguish between students with inflexible or limited strategy choices (e.g., Student A) and students with flexible and advanced strategies (e.g., Student B). 


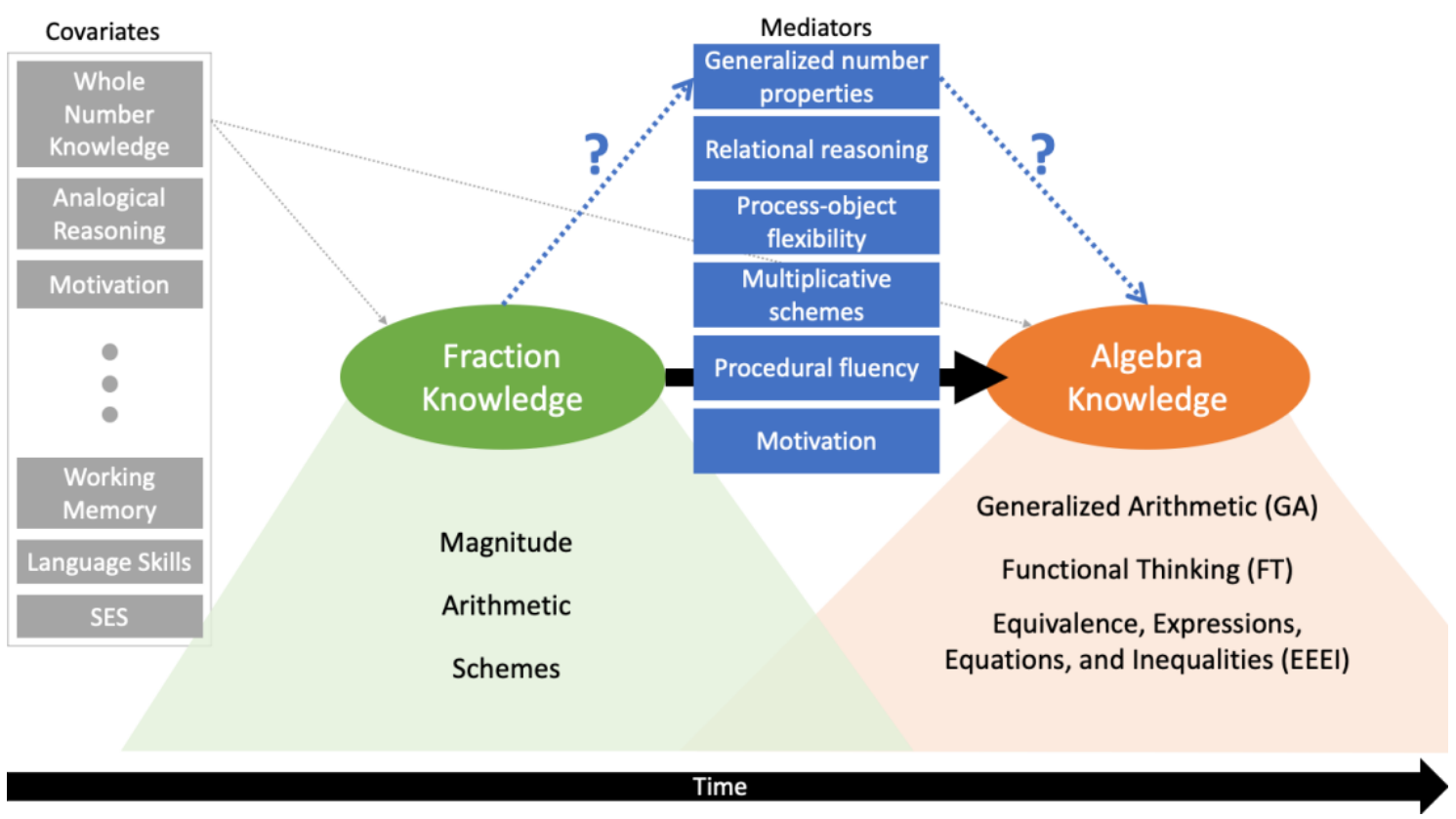

Figure 8. Conceptual model of how fractions knowledge may lead to algebra knowledge. Students' cognitive, affective, and demographic characteristics influence both types of knowledge (grey). As discussed throughout this review, fractions knowledge may influence algebra through many possible mediators (blue). Future studies should test these paths. The green and orange shaded regions indicate that both fractions and algebra contain many subconstructs and develop gradually over time. 